\title{
Observations and Experiments on Sex-Change in the European Oyster (0. edulis). Part III. On the Fate of Unspawned Ova. Part IV. On the Change from Male to Female.
}

\author{
By \\ J. H. Orton, D.Sc., \\ Department of Zoology, the University, Liverpool.
}

With Text-Figures 1 (Part III) and 1-7 (Part IV).

\section{CONTENTS.}

Part III. On the Fate of Unspawned Ova . . . . . . . 2

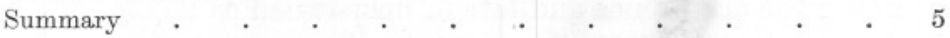

Part IV. On the Change from Male to Female $\quad . \quad$. $\quad . \quad$. $\quad . \quad 5$

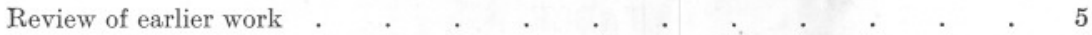

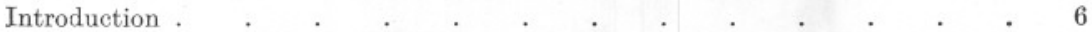

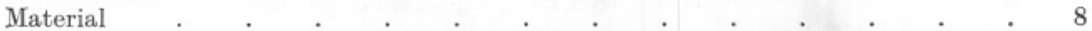

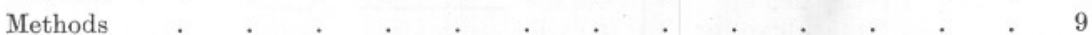

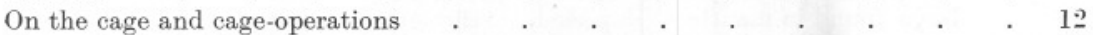

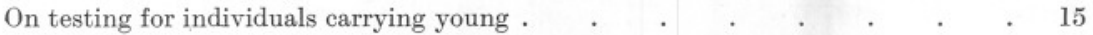

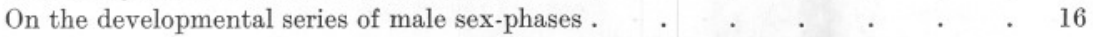

Series A. Experiments on oysters proved to be male $\quad . \quad$. $\quad . \quad$. $\quad . \quad 17$

Experiment 1. West Mersea, R. Blackwater, $1922 \quad$. $\quad . \quad$. $\quad . \quad$. 17

Experiment 2. West Mersea, R. Blackwater and R. Yealm, near Plymouth, 1923

Experiment 3. R. Yealm, near Plymouth, $1922 \quad$. $\quad . \quad$. $\quad . \quad 23$

Summary of three experiments on sex-change in samples of male oysters $\quad$. $\quad 24$

Conclusions . . . . . . . . . . . . . . . 27

SERIEs B. Experiments with oysters bearing young . . . . . . . $\quad 27$

Experiment 4. On females bearing young (1922), West Mersea, R. Blackwater 28

Experiment 5. On females bearing young (1922). Relaid R. Yealm . . 30

Experiment 6. On females bearing young (1923), West Mersea, R. Blackwater 31

Experiment 7. On females bearing young (1923), R. Yealm, near Plymouth 32

Experiment 8. On females blacksick, July 1924, West Mersea, R. Blackwater 34

Experiment 9. On females whitesick, June-July 1924, West Mersea, R. Blackwater . . . . . . . . . . . 34

Experiment 10. On females (West Mersea and Fal Estuary) blacksick, July 1925, West Mersea, R. Blackwater . . . . . . . . 35

Experiment 11. On females (West Mersea and Fal Estuary) whitesick, July 1925, West Mersea, R. Blackwater . . . . . . . $\quad$. 35

Experiment 12. On females bearing young, 1926, Truro beds, Fal Estuary . $\quad 36$

Experiment 13. On females bearing young, 1926, West Mersea, R. Blackwater 37 NEW SERIES.-VOL. XIX. No. 1. AUGUST, 1933. 
Experiment 14. On isolation in the sea of ripe females, West Mersea, R. Blackwater, 1923 . $\quad . \quad . \quad . \quad . \quad . \quad . \quad . \quad . \quad . \quad 38$

Experiment 15. On isolation in the sea of hermaphrodites, West Mersea,

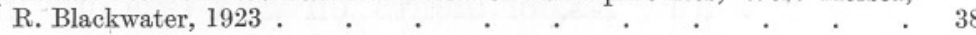

Summary and discussion of experiments on isolating oysters carrying young (Series B) and on those with ripe eggs (Series C) . . . . . . 41

Conclusions from experiments on oysters with young . $\quad . \quad$. $\quad . \quad$. $\quad . \quad 44$

Sex-phases intervening between successive female phases . . . . . . . . 45

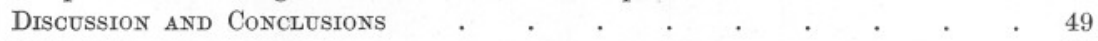

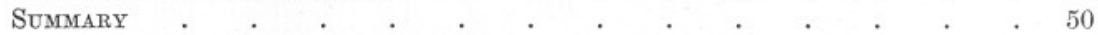

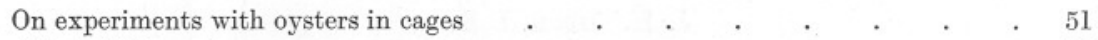

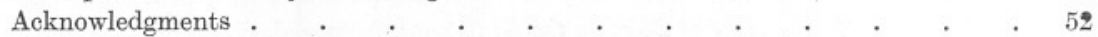

References . . . . . . . . . . . . . . . . . . . . 53

\section{PART III. ON THE FATE OF UNSPAWNED OVA.}

AN analysis of the quantity and distribution of unspawned eggs in the gonad of 0 . edulis recorded in Table IV, 1, 1927 (of oysters with young) and Table IX, 1, 1927 (of post-spawned oysters), gives useful information regarding the occurrence and fate of unspawned ova as may be seen from the figures given in Table A.

\section{TABLE A.}

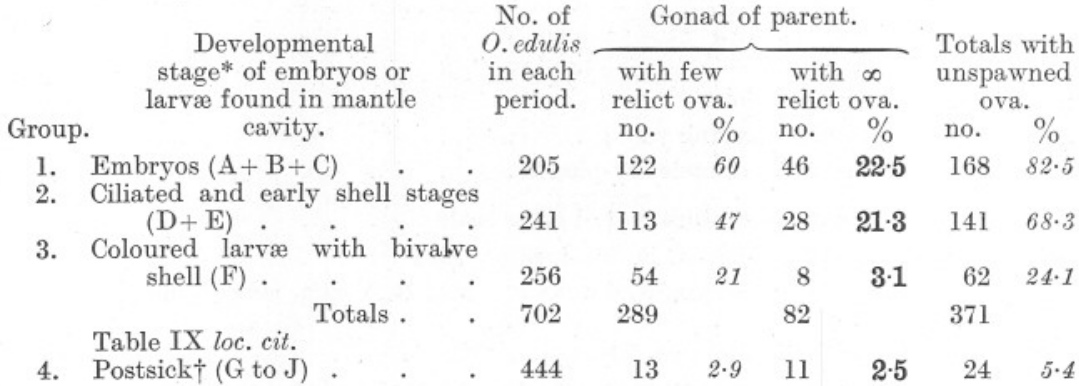

These figures show an important sequence correlated with the lapse of time after spawning; thus few unspent ova occur in $60 \%$ and many unspent in $22.5 \%$ of individuals in Group 1, which have recently spawned $(\mathrm{A}+\mathrm{B}+\mathrm{C})$, as is attested by the occurrence of only embryos in the mantle cavity. Many of these oysters spawned after the act of dredging, and may be considered to have spawned prematurely. Such individuals were doubtless on the point of spawning and some might have spawned if they had been left undisturbed, but it is probable that in a fair proportion spawning was precipitated by the act of dredging and the retention afterwards out of water.

* See I, p. 983 , for definition of these stages.

† Individuals carrying embryos or larvæ are designated "sick" by oyster-cultivators. 
Those individuals $(\mathrm{D}+\mathrm{E})$ which were carrying ciliated or partially shelled larvæ (aged 3 to 4 days) had clearly spawned naturally on the beds before being dredged. Nevertheless $47 \%$ of them showed a few unspawned ova, and $21 \cdot 3 \%$ many. Oysters with coloured and fully shelled larvæ (F), however, show only $21 \%$ with few and only $3 \cdot 1 \%$ with many relict ova. After extruding their larvæ a total of 444 oysters ( $G$ to $J$ ) showed only $2.9 \%$ with few ova with the addition of only $2.5 \%$ with many unspent ova.

The decreasing percentages of unspawned ova in the parents correlated

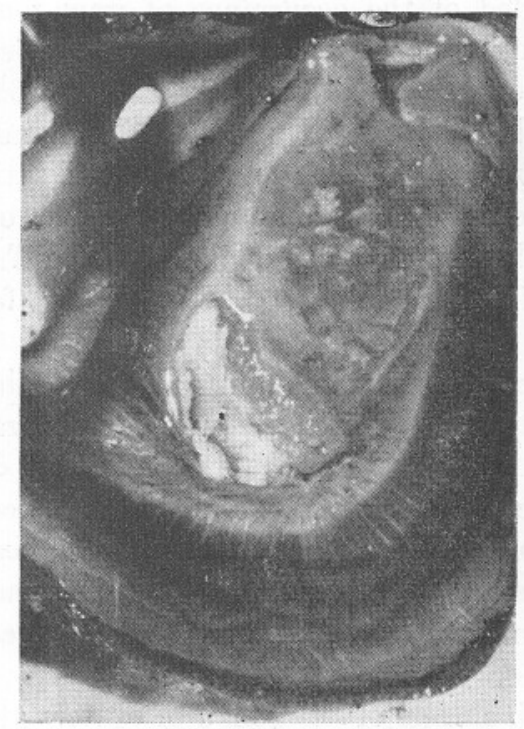

FIG. 1.-Photo of visceral mass of $O$. edulis living showing one large and several small patches of unspawned ova. The large patch is in the centre of the visceral mass. $\times$ ca. 2 . (Photo by A.J.Smith.)

with $(a)$ the increasing age of their larvæ and $(b)$ the post-sick phase, clearly show that it is normal for unspent eggs to be voided from the gonad after the main act of egg-spawning. The sudden drop in the percentage between Group $2(\mathrm{D}+\mathrm{E})$ and Group $3(\mathrm{~F})$ is critical, since all the individuals in these groups spawned naturally on the beds; it indicates that the voiding of unspawned ova is effected largely at the time the parent is carrying well-developed larvæ. This process is continued after the larvæ are extruded, but appears to be still incomplete in $5.4 \%$, of which $2.9 \%$ are negligible. The residual $2.5 \%$ of cases with numerous unspawned ova among post-sick phases are noteworthy.

Confirmatory evidence of the extrusion of relict ova after spawning has 
been obtained in seasonal studies of oyster populations, but information so obtained is less easy to present and is perhaps less satisfactory than such convincing figures deduced from data already published-as are given above.

The different percentages obtained for Groups 1 and 2 in Table A are in part a measure of the differences resulting from premature and natural spawning, but since relict ova are shown to be extruded in bulk when the embryos are only a few days older (in Group 3) it is possible that this process may begin soon after the spawning act. In Table IV, loc. cit., 12 instances are recorded of the occurrence of numerous to $70 \%$ unsegmented eggs occurring along with embryos in the mantle cavity, and many similar instances are recorded in 2, 1927. It is probable that in these spawning individuals extrusion of unfertilised ova may have occurred after the main spawning act. In some cases fertilisation had occurred, so that larvæ of different ages were found together in one oyster. These facts already published confirm the deduction from Table A that relict ova may be voided from the gonad soon, i.e. within a few days, after the main spawning act.

In the event of relict ova remaining in patches in the gonad (see Fig. 1) the body of the oyster often presents an appearance to the naked eye designated as "curdley." It would appear that degeneration with absorption of these eggs usually and possibly always occurs.

Microscopic sections of a number of different types have confirmed observations on fresh material that degeneration usually occurs, but extensive exploration of preserved types is required to learn what happens in all circumstances.

In examining fresh smears of the gonad of oysters at the beginning of the breeding season when eggs are developing rapidly, the possible occurrence of new or old (i.e. last season's) relict ova is a disconcerting factor, and great care is needed in assessing the effective sexual condition of the material examined. There can be little doubt that mistakes have been made in this respect by both experienced and inexperienced workers.

The proportion of females found incompletely spawned while carrying young varies in different seasons, and is probably usually slightly higher at the beginning of the breeding season on most grounds. In Table IV, 1, there are incompletely spent $65 \%$ (163) in June ; $57.5 \%$ (256) in July ; $45 \%$ (182) in August; $48.5 \%$ (95) in September; and $16.7 \%$ (12) in October. The numbers in brackets give the total examined each month, and the monthly grouping gives a close approximation to the course of the spawning season on the different beds whence material was obtained.

Abnormal incomplete spawning was found on the Fal Estuary beds in 1927 and is discussed in 2, pp. 403-4. 


\section{SUMMARY.}

An analysis is made of the records of unspent ova in the gonad of 1146 oysters $(O$. edulis) with-or recently with-young. High percentages of gonads with relict ova occur within a few days from spawning, much smaller percentages a few days later and still smaller ones one to two months after spawning. It is inferred that unspent ova are normally and mostly extruded from the gonad within a few days after spawning; confirmatory evidence for this view is adduced from published observations. It was found that masses of relict ova may be retained in the gonad for a longer period in about $2.5 \%$ of recently spawned females. It is pointed out that if these residual ova were fertilised upon extrusion they would give rise to a successful but spurious second spawning.

\section{REFERENCES.}

1. Orton, J. H. Journ. Mar. Biol. Assoc., N.S., Vol. XIV, p. 967, 1927.

2. do. Nature, Vol. 120, p. 403, 1927.

\section{PART IV. ON THE CHANGE FROM MALE TO FEMALE.}

\section{Review oF EARLIER Work.}

SINCE the year 1920 the writer has been accumulating evidence on the problem of sex-change in the European oyster, O. edulis. In 1927 (1) the relevant literature on the subject was reviewed and an outline given of the observations and experiments being made with a view to obtaining critical information regarding sex-changes $(1$, p. 969). The first part of the projected programme consisted in the examination of the gonad of more than 1000 individuals at various periods after the extrusion of ova from the gonad. This part of the programme was accomplished by laboratory and field observations and by isolating proved and spawning females in tanks and in cages in the sea. The results of this work were published in 1927 (1), wherein it was demonstrated :-

(1) that among 702 individuals carrying young $97 \cdot 3 \%$ were found in some phase of developing maleness;

(2) that development of sperm-morulæ begins normally in the gonad of oysters within a few hours after the act of egg-extrusion;

(3) that this development normally accelerates in the course of a few days, so that by the time the oyster is carrying black-coloured larvæ the gonad contains ripe sperm-morulæ (in many such individuals the gonoducts are also full of ripe sperm-morulæ ready to be discharged, see 2, Fig. 1, p. 316.) ; 
(4) that this phase of sperm-development attains a peak within one to two months after the act of egg-spawning and then wanes, if spawning has occurred early in a normal season on a productive type of oyster bed, e.g. West Mersea, River Blackwater, Essex; or Upper Fal Estuary; or Whitstable beds, Thames Estuary. The probability was discussed that this phase of sperm-development may be slowed down or arrested in the autumn and winter in individuals spawning as females late in the breeding season (see 3, Table VI, category 21), and be completed in the following spring and early summer. Evidence on this aspect has since been accumulated and is presented in this paper.

(5) that a variety of intersexes (or mixed sexes) occurs, some of which can be recognised by naked-eye inspection.

In 1928 the breeding period of the oyster was discussed (3) in a general way in relation to spring and autumn periods of shell-growth (increase in shell area). In that paper (p. 399 and Table VI) is given an analysis of the sex-condition in October and November 1927 of some 1800 oysters from the beds in the Upper Fal Estuary. Thirty categories of individuals in different sexual or physiological conditions are recognised. A study in the seasonal variation of these categories during 1926 and 1927 has been made and will be discussed later in its bearing on sex-change in the population. In 1931 figures were published (2) of the gonad of the oyster at successive stages after the act of egg-spawning. Some results of experiments on the change of sex from male to female were given in the paper (1) (1927, lots 106 to 115 в, pp. 1027 to 1033), but a discussion of the results was reserved for a separate publication. The portions of the original programmes of work dealing with the experiments on sex-change from male to female, 1, p. $969(b)$ and $(c)$, are given in the following pages. A statistical investigation of seasonal sex condition in oyster populations from data already collected and extending over a period of three years is being undertaken along with other work, and a full discussion of the sexphysiology of the European oyster is reserved for a later publication.

\section{INTRODUCTION.}

During the period 1922-27 experiments were designed and carried out in the River Blackwater, in the River Yealm near Plymouth, and on the Fal Estuary to obtain evidence of the change of sex in individuals of O. edulis from male to female. These experiments have been partially successful inasmuch as this sex-change has been detected in a relatively small proportion of individuals (i.e. ranging from 10 to $50 \%$ ). An ideal experiment should give sex-change in very nearly $100 \%$ of the animals. The change in sex from male to female is clearly not of the same auto- 
matic nature as that from female to male; moreover, the recognition of a female phase will be lost if individuals spawn as females and evacuate their young in the interval between successive examinations of the experimental oysters, for such spawning individuals revert rapidly to the male condition as is now abundantly proved (1). The knowledge acquired in the course of these experiments would be used, it was hoped, to design more promising experiments on a larger scale, but the recent shortage of oysters on most English beds (4) has interfered with this project.

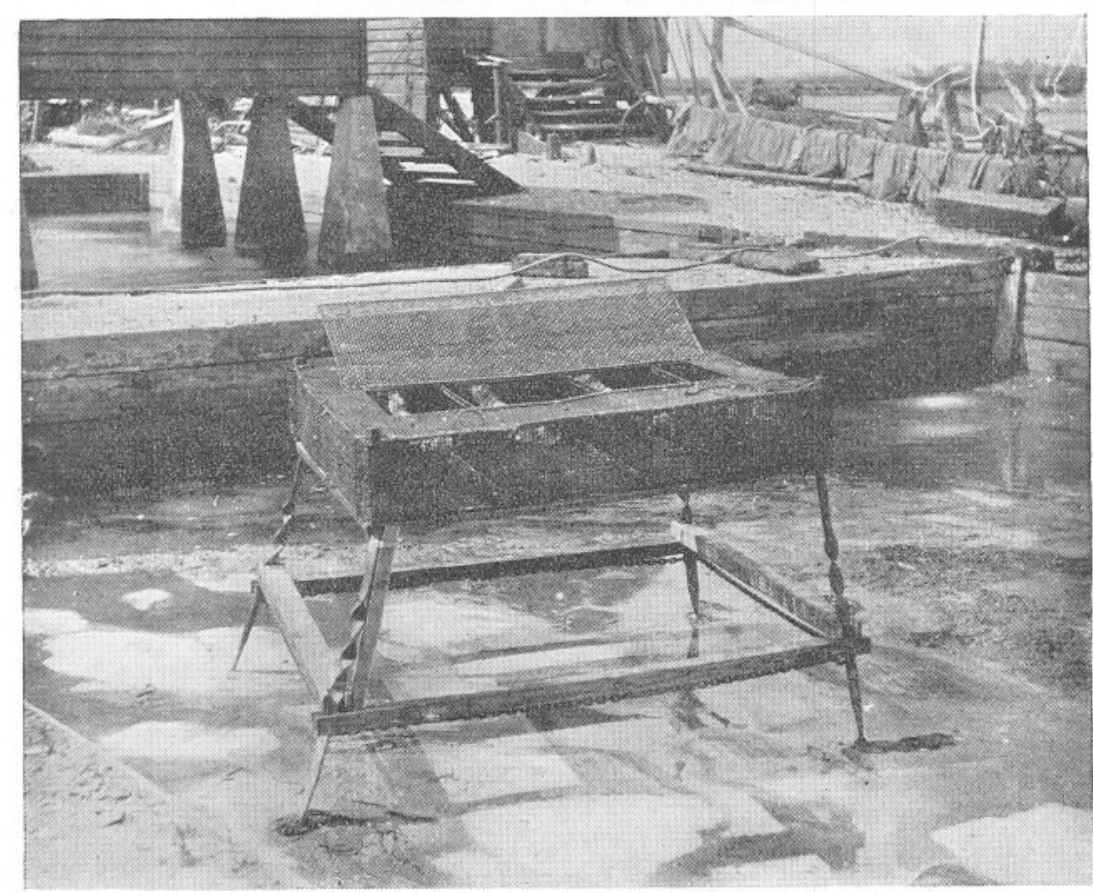

FIG. 1.-View of the experimental oyster cage used at West Mersea, showing the oyster pits at low water.

The chief difficulty in carrying out experiments on change of sex in oysters lies in keeping the experimental individuals under healthy conditions while at the same time taking precautions to isolate them unimpeachably from others. The writer holds the view that for work of this kind, the animals should live under conditions as nearly natural as possible. It was therefore decided to fix the site of the experiment on grounds where oysters form natural beds so that there can remain no doubt of the suitability at least of available water and food.

In order to isolate the experimental material and render recovery easy, a large cage 6 feet by 5 feet by 10 inches deep made of iron wire mesh 
( $\frac{3}{8}$ inch in diameter) was designed and used for the work (see Fig. 1, p. 7). This cage was divided by permanent partitions into four compartments, two large and two small, so arranged that each compartment could be recognised without the provision of a label (see Fig. 2, p. 10). This device proved extremely useful in dealing with heterogeneous material. Oysters in a known sex-condition at a known time were placed together in one compartment; individuals were mostly easily distinguished by tracing the outline of the shell and adding drawings in situ of barnacles and other permanently attached growths; some shells not otherwise easily recognised were marked with a distinctive file-mark. In special cases a small cage was constructed and attached inside the large cage to isolate an individual. The practical difficulties of maintaining an experimental cage of this kind on a commercial oyster bed for a number of years are very great; it was only by the hearty co-operation and good-will of the Directors and employees of the Tollesbury and Mersea Native Oyster Company that experiments in the River Blackwater were rendered possible; the difficulties of experiments on the River Yealm near Plymouth were overcome by the personal interest of Mr. J. Kingcome and the Director of the Yealm Oyster Fisheries. On the Fal Estuary where the beds are public, experiments had to be confined to the summer period, when the beds are closed for general dredging; permission for these experiments was courteously given by the Truro Oyster Beds Committee and rendered possible by the help of Mr. E. Searle and many oyster-dredgermen.

\section{Material.}

The oysters used in these researches were obtained by dredging in the breeding season chiefly at West Mersea, River Blackwater. Some were also obtained from other English grounds, namely Fal Estuary, Whitstable, River Yealm, and the River Helford. The age of the experimental oysters varied from about 3 to 7 years, but was estimated at being mostly from 4 to 6 years. In the earlier years, from 1922, the average age would probably be greater than later when the larger individuals were becoming relatively scarce. It is a difficult matter to obtain large numbers of oysters carrying young without destroying these valuable molluscs. The writer was fortunate at West Mersea in being able frequently to examine catches of many thousands dredged for the purpose of relaying, and at the same time of following the course of the breeding season. On productive beds such as occur at West Mersea, it is desirable to find out each year when a significant proportion of oysters have reached the blacksick stage, in order to make preparations for putting out clean shell at a time which will coincide as nearly as possible with the probable settling time of the oyster larvæ. The examination for spawning oysters 
is therefore a routine operation, of which advantage was taken to collect as many young-bearing individuals as possible. When oysters with young are kept out of water for some time a proportion will often exude a few embryos or larvæ from the edge of the shell, having opened the shell presumably in response to some stimulus, such as the need to respire, whereupon a few of the young flow out of the shell with a little of the mantle liquor. It is possible that the embryos themselves provide the stimulus for the opening of the shell merely by exerting continuous unusual pressure upon sensitive parts of the mantle. Individuals suspected of carrying young may be tested as described on p. 15 .

Early in the breeding season $1 \%$ of a sample may be detected as female spawners after exposure to air on warm nights, while later in the season as high a proportion as $7 \%$ may be found in this way.

On beds where oysters are not caught in bulk in summer the experimental oysters were obtained as is described on p. 15, or in process of opening large samples.

\section{Methods.}

The experiments on sex-change from male to female were of two kinds :-

(A) A total of 313 individuals, proved to be male at the time of examintion (usually about July), were isolated at different times and places in one compartment of the cage and returned to the oyster bed (see Fig. 4, p. 13). These oysters were taken out of the sea after various intervals of time-usually about a year later-and tested at intervals during the ensuing spawning season for individuals carrying young. In this kind of experiment only those females which were actually carrying young at the time of examination could be detected. If individuals spawned and released their young during the interval between successive examinations, their sex-change would not be known. It was considered imperative to return the oysters to the natural habitat as soon as possible after examination in order to maintain normal and healthy conditions of growth and gonad development. Although sex-change was found in experiments of this kind there can be no doubt that the actual percentage of individuals undergoing sex-change was greater than was observed.

As a variation of this experiment samples of the material were opened at various intervals after the beginning of the experiment and examined macro- and micro-scopically for stages of development of femaleness.

The detection of males for experimental purposes was effected by examining the contents of the gonad extracted by means of a fine pipette passed through a boring made in the shell of the oyster (see Fig. 3, p. 11). Only those individuals were selected as "male" which yielded only sperm-morulæ. Hermaphrodite individuals and any others from which 
eggs as well as sperm-morulæ were obtained were rejected.* The individuals selected were therefore essentially passing through one or other of the male phases (see p. 16). The shell boring was made in the left valve from a position varying from postero-dorsal to sub-median (see Fig. 3). From this position the gonad can be tapped near the surface of the body (see 5, 1924, Plate XII) with relatively little risk of damage. In some instances the intestine was perforated.

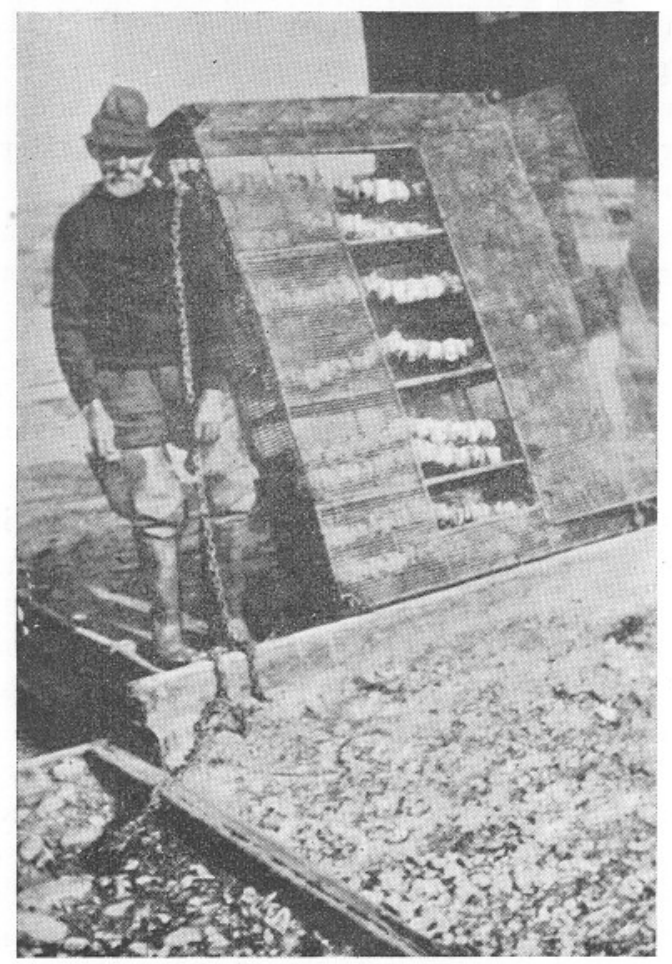

FIG. 2.-View of the experimenta oyster cage, dismantled and prepared with shells for catching oyster and Crepidula spat.

The experimental oysters mostly recovered easily and well from this operation (see pp.18,23), though doubtless some of the mortality which subsequently occurred was caused directly or indirectly from the operation. The boring in the shell was observed in some cases to be quickly sealed by deposition of a horny or calcareous membrane derived from the epidermis of the oyster ; the body wound also healed quickly but sometimes formed a scar. In a few cases the perforation of the shell was so well sealed

* In Experiment 1 a few males with obviously relict ova were accepted. 
internally (see Fig. 3, B, D) that a drill had to be employed to expose the body again; usually the new shell was thin and could be broken with the assistance of a small steel instrument. Sympathetic deposits sometimes occurred on the right valve (see Notes, p. 25).

A.

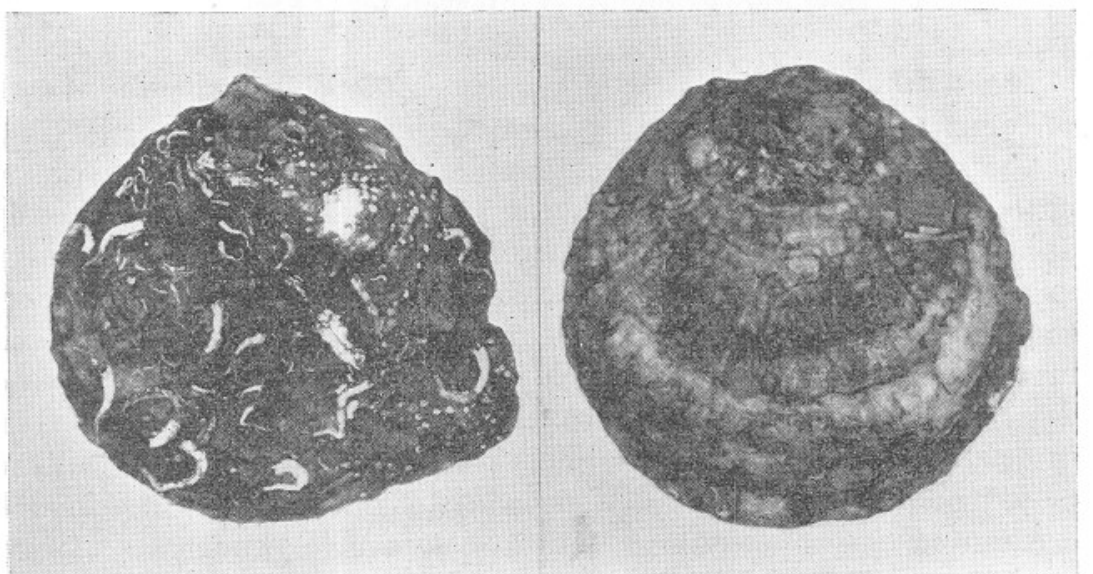

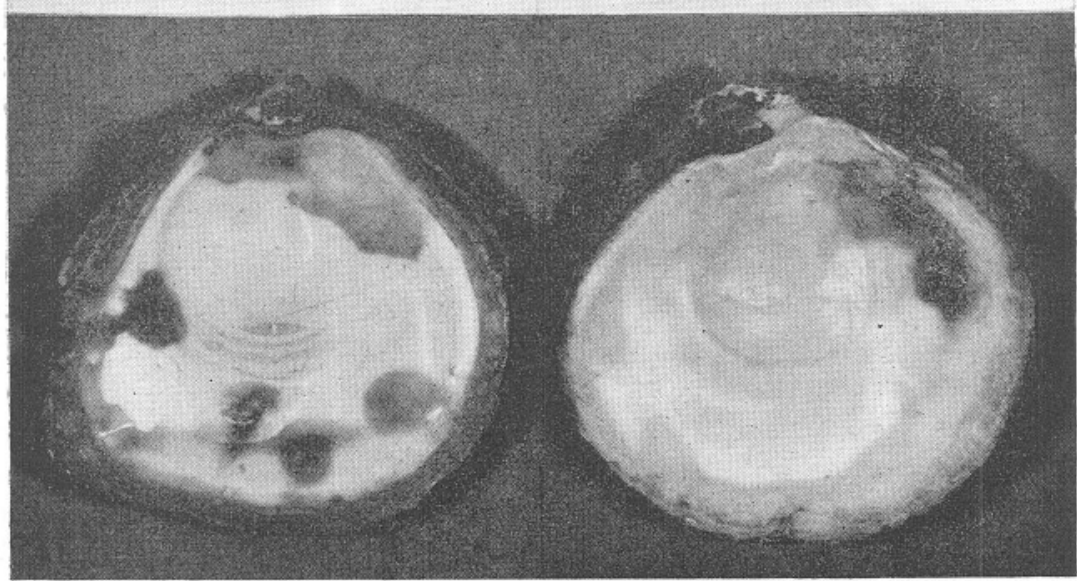

B.
D.

FIG. 3.-Views of external and internal faces of two bored left valves of $O$. edulis from Experiment $3 . \times c a \cdot \frac{5}{8}$. (Photos by P. Bond.)

$A$ and $B$ views of one valve. In $A$ the boring is well shown near the umbo on the right. In B the site of the boring is near the umbo on the reader's left, and is covered with nacreous shell. The dark area extending from the boring is due to infiltration, but is little more than a stain on the shell itself.

$\mathrm{C}$ and $\mathrm{D}$ are views of another valve also showing perfect sealing of the boring internally. The site of the boring in $\mathrm{D}$ is near the umbo on the reader's left ; the sealing is perfect.

(B) As adequate proof has been obtained that spawning females change normally - to the extent of $97 \%$-into males immediately after the 
spawning act (1), it is sufficient to isolate individuals carrying young to obtain thereby a collection of males in the early stage of developing the male phase. Samples of oysters (amounting to a total of 663 individuals) bearing young were therefore isolated in compartments of the cage in the years 1922-25 and 1927, and kept in the sea for periods of months or years during which they were examined at intervals for the return of the female phase.

The reliability of this kind of experiment depends upon the degree of completeness of the egg-spawning act. There can be no doubt that the normal method of egg-spawning results in the extrusion of all or most of the eggs in the gonoducts and gonad at one and the same time (see 6 ), although $50 \%$ of egg-spawners may retain a few to many scattered eggs in the gonad; nevertheless, the experience gained in examining more than 1000 spawning females, as well as many thousands of other specimens throughout the seasonal cycle of sex changes, indicates that in a few cases females incompletely spawned at the first attempt may spawn successfully again as a female within a period varying from a few days to more than a month. Successive spawnings of this kind, it will be noted, occur from one batch of eggs and do not involve two phases of eggproduction. The fate of unspawned eggs is discussed in 1, p. 976, and 6, in this issue of this Journal ; the significance of two acts of egg-spawning from one phase of egg-production will be discussed later with the results of the experinients.

\section{On the Cage and Cage Operations.}

The experimental cage with its addition of legs is shown in Fig. 1. Legs were found to be desirable to avoid the accumulation of mud which occurs even in an open iron wire-meshed cage lying on the bottom in such silty water as occurs in the Blackwater creeks. The meshes of the cage were $\frac{3}{8}$ ths of an inch square. In the earlier experiments when the cage lay on the bottom a disastrous mortality and weakening of the oysters accompanied the accumulation of mud in the structure. The cage itself could be removed from the collapsible table structure and was conveniently placed in sea-water in the pit, shown in Fig. 5, p. 14, underneath the storeroom, which was used as a laboratory. As the experimental material was prepared it was transferred direct to its appropriate compartment in the cage and maintained conveniently in sea-water. During spring tides the sea-water in these pits is well and frequently renewed (see Fig. 5).* The compartments of the cage and central lid on one face - so constructed as to prevent loss of material in the event of the lid being forced open -with the strengthening rods and tubular corner sockets for

* During neap tides it was noticed that Ciona intestinalis especially seemed to find conditions intolerable in these pits. As the water and aeration appeared to be good, the lethal condition suspected was the exposure to very strong sunlight. 
A.
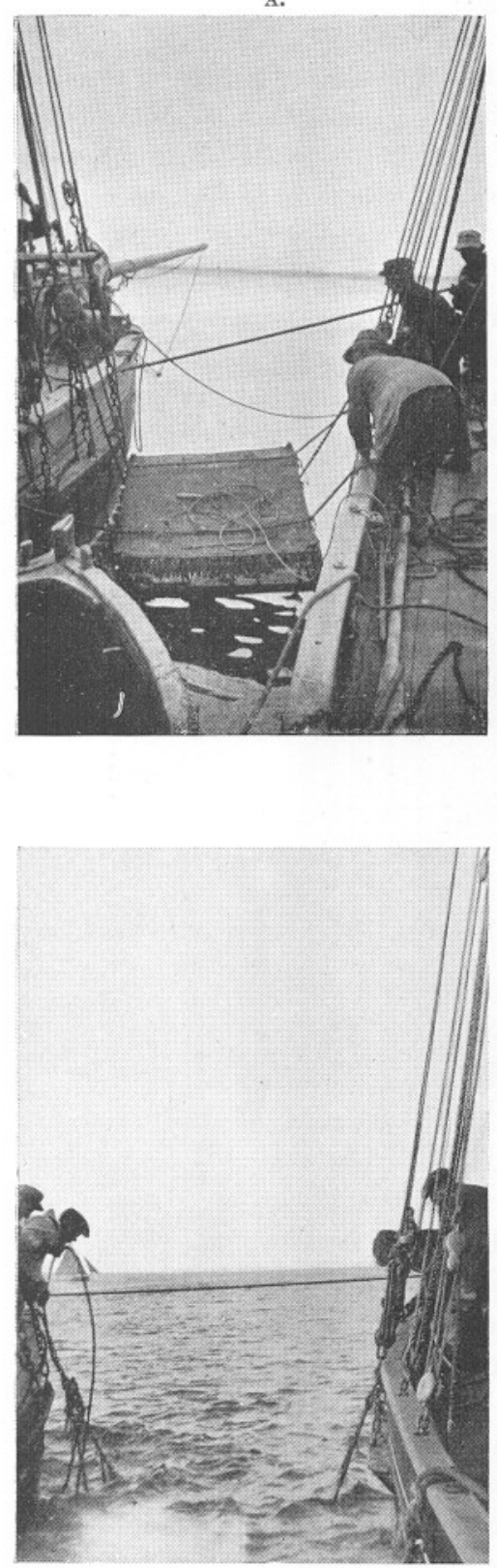

B.
D.
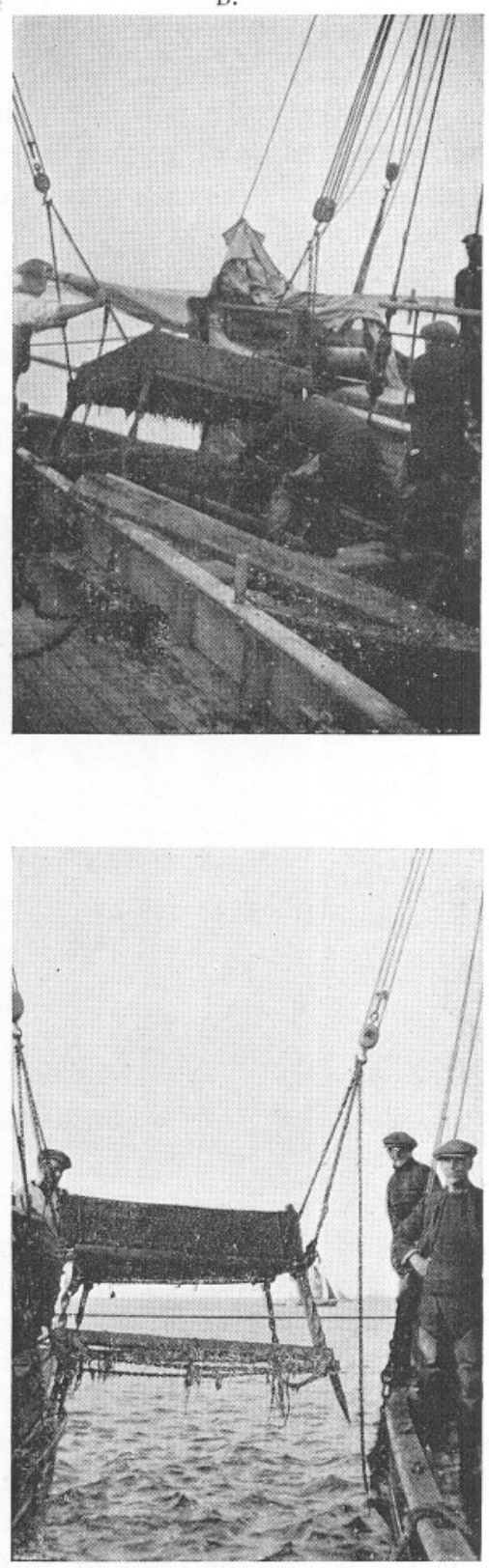

C.

FIg. 4.-Four views of the operations in putting out and hauling the experimental cage.

A. The skiff has been withdrawn from below the cage, which is now being lowered into the water.

B. Hauling the cage after recovery of the anchors and chains.

C. Cage hauled clear of the water to permit the passage below it of the skiff.

D. Cage being lowered into skiff, preparatory to conveyance to the oyster-store. 
the legs are seen in Figs. 1 and 2. Four narrow iron bars with end-holes fitting on the upper part of the legs formed a skeleton table on which the cage rested (see Fig. 1). The tops of the legs projecting through the corner sockets of the cage were threaded so that the cage could be secured by good bolts.

The cage was assembled on its table and the experimental material enclosed while the apparatus was on the foreshore, or in a large flatbottomed boat, a skiff beached near by. At low water the skiff was towed to the Deeps (9, see Chart, Fig. 2) and manœuvred between two anchored and yoked dredging-boats. The cage was then hoisted by its anchor

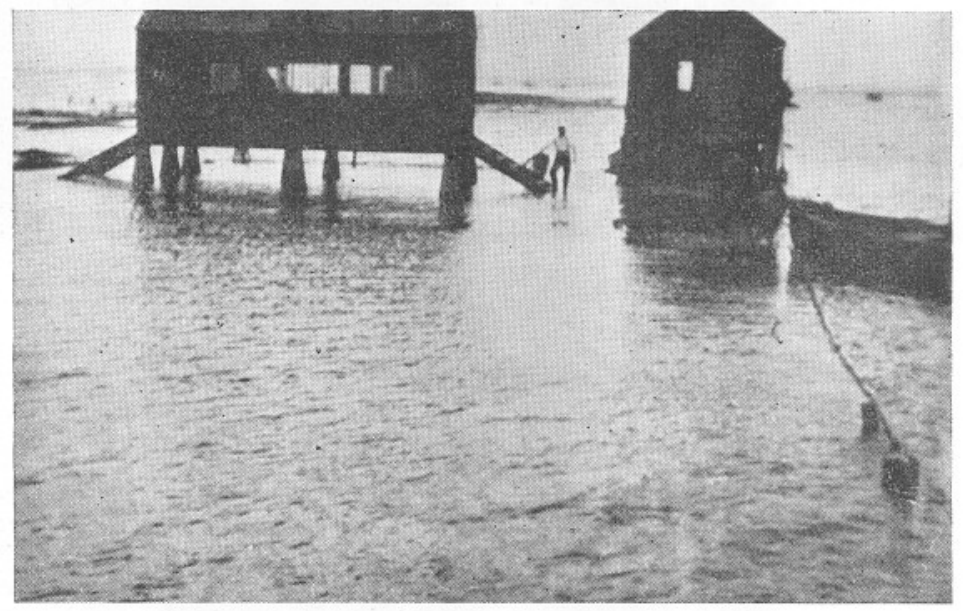

FIG. 5.-View of the oyster pits flooded at high water, showing the oyster store on the left used as a laboratory.

chains, which were secured to the legs, and the skiff removed (see Fig. 4, A, p. 13). Ropes were then run through pairs of handles on the top edges of the cage, and lowering gradually proceeded with until the bottom was reached. Bearings were then taken. The anchors, two in number, were run out separately, held and lowered by ropes until taut, when the rope was slipped and hauled in. A lead with line was left on the cage for testing the position of the cage at the end of the operations.

In hauling, the anchors were first creeped, then the two boats anchored in position with the cage anchors and chains aboard. The cage was then hauled and well washed; the skiff was run under it while clear of the water (see Fig. 4, B, C, and D). In a clean haul the cage could be dropped snugly into the skiff and taken at once to the store for further washing and examination of its contents. When the cage had lain undisturbed on the beds during the winter an accumulation of mud was always 
found in it. On the site of the experiment there was a depth of two fathoms at low water; the same site was used in all the experiments carried out at West Mersea, River Blackwater.

\section{On Testing for Individuals Carrying Young.}

In testing for individuals incubating embryos or larvæ in the mantle cavity at the time of examination, the adults, after being washed or scrubbed, were usually laid out with the flat valve downwards on glass plates on a temporary bench in a room serving as a laboratory. In warm

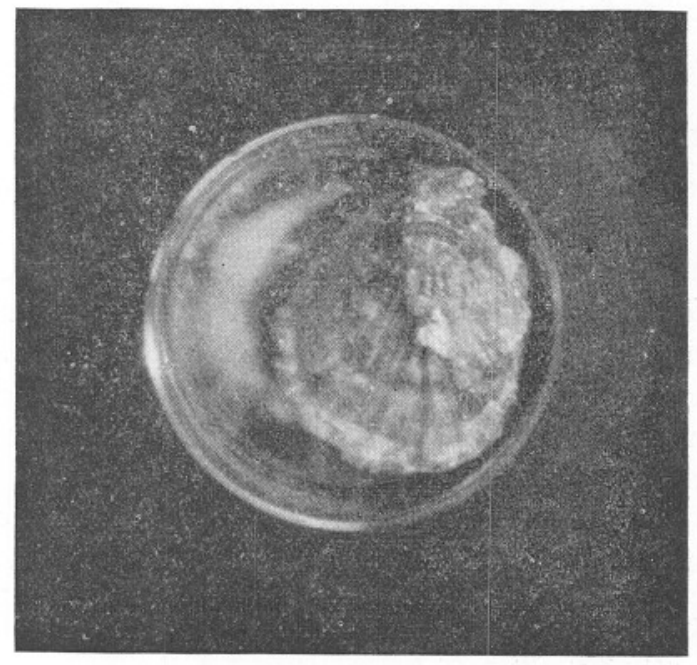

FIG. 6.-Photo of $O$. edulis found to be carrying young by the method of testing in small dishes $-\times$ ca. $\frac{1}{3}$.

The white mass on the reader's left, concentric with the shell, is composed of hundreds of thousands of larvæ.

weather under these conditions oysters will often soon extrude a few embryos or larvæ at the edge of the mantle. The sample was usually left under these conditions overnight, covered in hot weather with a damp cloth, the young-bearing individuals being isolated in sea-water in shallow dishes as they were detected. On transferring young-bearing forms to water in a dish a certain number of the young are usually soon extruded into the water (see Fig. 6, above), thus permitting confirmation of the first indication of the gravid condition.

The oysters which failed to extrude larvæ on the bench were each again washed and isolated in a small dish of sea-water. The water in these dishes was renewed at intervals for one or two days, during which careful examinations were made. Usually the gravid individuals would 
evacuate a large portion of their young sooner or later, but sometimes the young were retained tenaciously. To detect these latter cases without injury advantage was taken of any such oyster opening its shell-valves widely to close the valves forcibly and quickly by hand-pressure. In this way a volume of water was suddenly expelled from the mantle cavity, carrying with it a number of larvæ if such were present. Widely open oysters could be examined by the naked eye.

This method of testing was efficient, but necessarily involved a constitutional strain on the material, especially when repeated after short intervals, and no doubt contributed towards delay in sex-development and the high mortality found during the experiments. A quicker method of testing, which avoids injurious effects, is desirable in future experiments.

\section{On the Developmental Series of Male Sex-phases.}

In a study of the state of the gonad at various intervals of time after egg-spawning it was convenient to establish an arbitrary series of possible conditions of the gonad (1, p. 981). Ten such arbitrary categories in the condition of the gonad with regard to the development of sexcells were instituted (loc. cit.). Among these ten categories, numbered in succession I to X, it was found that seven (numbers III to IX) form definitely a series of sex-phases in the development and history of maleness. This series is given below in Table B and renumbered I to VII. A stage VIII is recognised, in which all the male elements have been evacuated from the gonad. This stage is neuter, but is historically related to the male-phases, and is conveniently retained as No. VIII in succession to No. VII.

For convenience the old arbitrary category numbers are given against the serial numbers of the sex-phases.

\section{Table A. The Developmental Series of Male Sex-phases.}

No. of

male

sex-

phase.

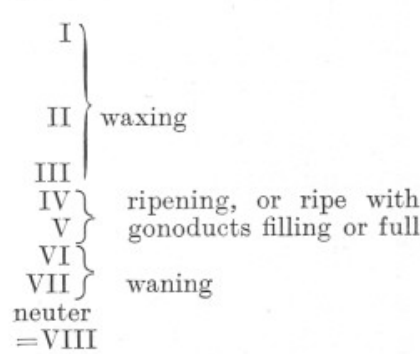

$\begin{array}{lllr}\begin{array}{c}\text { Rex-cells present in gonad. } \\ \text { Developing }\end{array} & \begin{array}{c}\text { Ripe } \\ \text { unspawned } \\ \text { ova. }\end{array} & \begin{array}{c}\text { Arbitrary } \\ \text { Category. } \\ \text { given in } 1 .\end{array} \\ \text { sperm-morulæ. } & \text { sperm-morulæ. } & \text { III } \\ \text { none } & \begin{array}{l}\text { a few to } \infty \\ \text { none or a }\end{array} & \text { vang up to } \\ & \begin{array}{l}\text { variable no. } \\ 40 \mu \text {. }\end{array} & \\ \text { f. } \infty \text { or } \infty & \text { do. } & \text { IV } \\ \text { none } & \text { over } 40 \mu . & & \text { do. } \\ \text { few or f. no. } & \infty & \text { do. } & \text { VI } \\ \text { f. } \infty \text { or } \infty & \text { f. } \infty \text { or } \infty & \text { do. } & \text { VII } \\ \infty & \text { f.no. to few } & \text { do. } & \text { VIII } \\ \text { f. } \infty \text { or } \infty & \text { none } & \text { do. } & \text { IX } \\ \text { f. no. to few } & \text { none } & \text { none or a } & \text { neuter } \\ \text { none } & \text { none } & \text { variable no. } & =\mathrm{X}\end{array}$

Abbreviations : no. $=$ number $; \infty=$ numerous ; $\mathrm{f} .=$ fair or fairly. 


\section{SERIES A.}

\section{Experiments on Oysters Proved to be Male.}

\section{Experiment 1. West Mersea, R. Blackwater, 1922.}

The details of the first experiment in investigating the change of male individuals into female are given in Table I. One hundred and fifteen males were identified from June 28 to July 7, 1922, and put in the cage in the sea on July 8 . The cage was left undisturbed and could not be examined until July 14, 1923, about one month after the breeding season had begun - when it was found to have become very heavily silted with mud, following heavy rains and much stormy weather. The accumulation of mud* had smothered most of the oysters and probably interfered with the normal development of those remaining. This experiment was regarded as a failure, and a new one begun at once; nevertheless, the surviving individuals were cared for and their sex-changes investigated.

Nineteen oysters survived the experience of the first winter, and of these four died in the summer following. None of the remaining fifteen were detected in a female phase from July 15 to August 2, nor from October 17 to 22,1923 . During the latter period oysters would not normally be expected to occur in spawn on the Blackwater beds, so that these oysters were in reality examined during the period of only two weeks of the spawning season. Some of these oysters may, therefore, very well have passed undetected through a female phase during the breeding season of the second summer $\dagger$-which in this year began late, about the middle of June, and extended into August and possibly into early September.

Six specimens were tested on July 15, however, and found to be males. Nine others were put in the cage to winter again. On June 7, 1924, 2 of these were found dead, and another died soon afterwards. In the 3rd summer of this experiment 6 individuals only were left; 2 of these produced either embryos or larvæ ; 1 was hermaphrodite and 3 were good males accumulating food reserves. One individual, carried through a third winter, was opened on July 16, 1925, again late in the breeding season, and found to be in the male phase.

\section{Summary of Experiment 1.}

Of 115 oysters proved to be males in July 1922, none were found to have developed a female phase in the next (2nd) summer. In the

* A large number of Ciona intestinalis (up to $15 \mathrm{~cm}$. long living contracted) and of Ascidiella aspersa (up to $7 \mathrm{~cm}$. long living and extended) were growing on the oystershells and on the cage, having survived-but no doubt assisted in-the deposition of mud.

$\dagger$ The summer in which an experiment is begun is designated the lst summer of the experiment; the summer in the following year is the 2 nd summer ; and the next following summer the $3 \mathrm{rd}$ summer of the experiment, and so on. 
3rd summer, 3 of the surviving 6 individuals became ovigerous or larvigerous. The larvigerous individuals were found developing a new male phase.

Heavy mortality occurred among the experimental oysters in the winter of 1922-23, and examinations for female phases were made during only a part of the breeding season in 1923 and 1924 .

Female phases may have been inhibited by the bad experimental conditions in 1922-23, and some may also have escaped detection in the limiting conditions of the experiment, i.e. the possibility of examining for individuals carrying young during only a portion of the spawning period.

\section{TABLE I.}

\section{Experiment 1.}

West Mersea, River Blackwater, on 0 . edulis proved to be male. June 28th to July 7th, 1922.

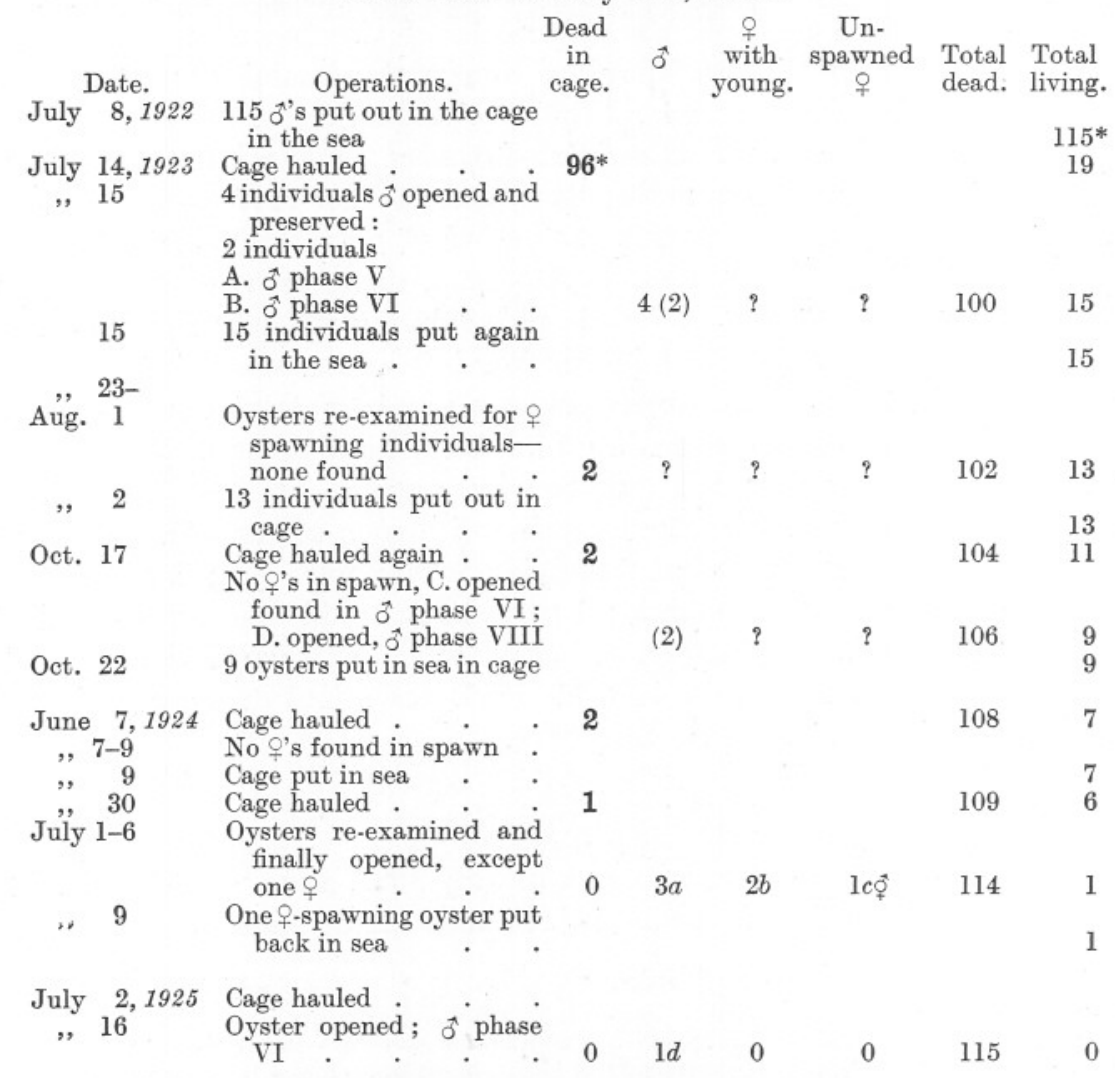

* Ninety-three of these shells were examined: 54 showed good recovery from the boring operation; 33 no recovery and 6 a bad recovery. 


\section{Notes to Table I.}

(a) The condition of these three oysters was as follows:Growth

of Shell

Fish. 1923.

1924. Length.

Recovery from Boring.

1. Good 9-10 mm. ? $64 \mathrm{~mm}$.

2. F.g.

?

$2-5 \quad 61$

a boss of nacreous material projecting into tissues which have grown well around it.

3. Good nil ? $2-5 \quad 65 / 82 \quad$ perfect

Sex-elements.

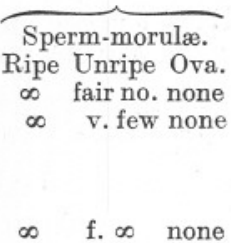

All three individuals were good male oysters accumulating reserve products.

(b) 1. One of these oysters extruded an enormous number of heliotrope coloured and shelled larvæ on July 1 . The shell boring was opened and the gonad tapped and found to be developing maleness giving $\infty$ ripe sp. m., $\infty$ unripe sp. mor., and no ova (phase IV). On July 6 the gonad was again tapped and found to be male in a later phase (VI). The shell of this oyster was then marked with a file and put back in the sea on July 9 . It was taken out of the sea on July 2, 1924, opened and found on July 16 to be in the $\delta$ phase VI (see $d$ ).

2. On July 6 the other oyster extruded during the night white embryos not ciliated; this individual was opened on July 8 after two days in the sea and found to be in 0 phase I with f. $\infty$ eggs left in spots in the gonad. It was therefore incompletely spawned but changing into the ot phase.
(c) 1. Good nil ?
$5-10 \quad 77$
perfect
$\infty$ none $\infty$ ripe

The gonad was of the type described as curdley : the individual had developed femaleness, and spawned incompletely as a female. This oyster had retained ripe spermmorulæ whilst acquiring ova, and had become hermaphrodite, but a functional female.

(d) The "d" individual found with young in 1923 had a gonad in male-phase VI.

\section{Experiment 2. West Mersea, River Blackwater, and River Yealm, near Plymouth, 1923.}

In the second experiment with oysters proved to be male the following improvements were made in the cage and procedure with a view to diminishing the limitations.

(1) The cage was mounted on legs (see Fig. 1, p. 7) to enable the silt to fall through the bottom of the cage, which formerly had rested on the river bed.

(2) It was decided to visit the cage twice a year to overhaul and clean the cage and its contents.

(3) After examining the experimental oysters at the beginning of the breeding season on the Blackwater beds in the 2nd summer, it was decided to transport the experimental oysters to beds near Plymouth, whence they could be hauled at intervals during the same breeding season. In this way more opportunities would occur for detecting individuals at the instant they were carrying young.

The details of Experiment 2 are shown in Table II, p. 22. During the period July 24-August 1, 1923, 101 oysters were found to be male by examination of the contents of the gonad extracted by means of a fine 
pipette from the living animal through a boring made in the shell. These oysters were put in the cage in Deeps on August 2, 1923. On October 17, 1923, the cage was hauled for the purpose of cleaning away accumulations of mud and growths* and for examination of the oysters. It was found that the cage had overturned.

The oysters were, however, in good condition and had grown remarkably fine shell-shoots, as indeed had most of the oysters on the dredging grounds. Tests were made for spawning individuals, although the spawning season was considered to be finished; no individuals were, however, found in spawn. A sample consisting of 18 of the experimental oysters was opened and examined (see note $a$, Table II). It was found that good

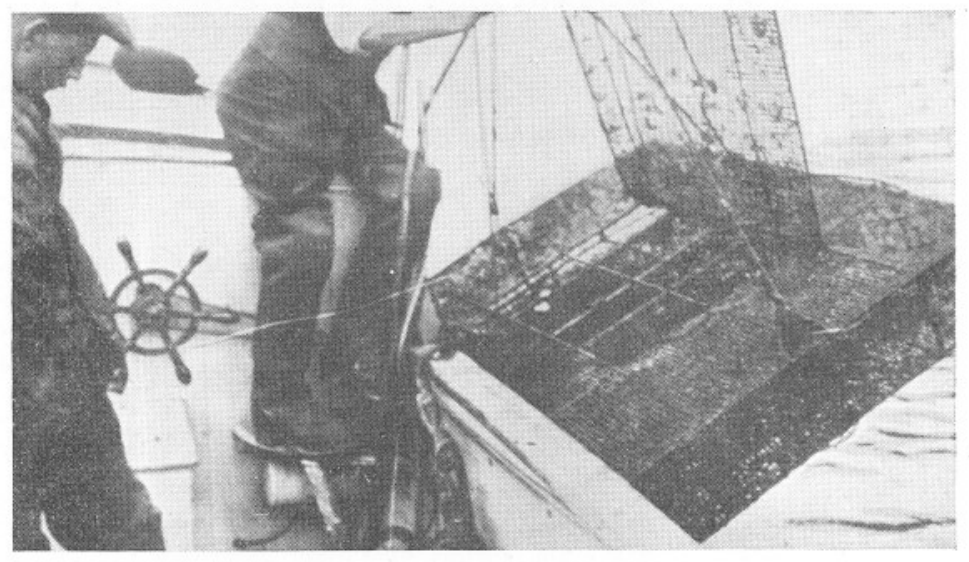

FIG. 7.-View of the smaller experimental oyster cage used in the R. Yealm being hauled from a motor-boat.

recovery from the operations of boring and tapping had mostly been made : new shell-material had been laid down on the inside of the shellperforation and effectively sealed the body from the external medium. Some individuals had made a poor recovery, but such might be expected to recuperate in the future. The mortality was low, amounting to $5 \%$. The sample consisted of 10 neuter individuals, some of which were in poor condition, but others were accumulating food reserves normally, and 8 still in the male phase, but mostly in a waning male phase. None was found certainly in a female phase, though No. 11 may have had a few young ova in the gonad.

The remaining experimental material was returned to the sea on the Deeps bed on October 22, and hauled the following summer on June 7,

* Ciona intestinalis up to $4 \cdot 3 \mathrm{~cm}$. long extended, Ascidia conchilega up to $2.5 \mathrm{~cm}$. long extended and medium Ascidiella aspersa were found in numbers and removed. These animals are an important factor in the accumulation of mud in a cage. 
when the cage was found upright, containing very little mud, and with a low mortality amongst the oysters. A very fine growth of colonies of Alcyonidium gelatinosum (commonly $10 \mathrm{~cm}$. long) covered the top of the cage and served on this occasion-and on others - to show how the cage had been lying on the sea-bottom.

At this time cold weather set in, and as none of the oysters were found in spawn on the day after hauling the cage, it was decided to put the cage back in the sea in Thornfleet Creek and examine it after a period of warmer weather. The cage was again hauled on June 30, and the oysters tested for females carrying young. Two such were found from July 1 to 6 , and as it was thought that no others were in spawn, the whole sample was returned to the sea, pending its removal to Plymouth. Quick transport was arranged and the experimental oysters were put out in another cage in the oyster beds in the River Yealm on July 15. This cage was hauled on August 6 and the oysters tested August 6-8 for those carrying young. Two of such were found and the remainder put back in the sea on August 8. Again the cage was hauled on August 26 and, after testing, three more young-bearing females were detected. The remainder were again returned to the sea, but unfortunately a site could not be obtained on the proper oyster bed, and the most promising site near the dredging grounds had to be adopted. This site proved quite unsuitable (see note $h$, Table V) ; nearly all the oysters died during the following winter and the experiment was concluded.

\section{Summary of Experiment 2.}

One hundred and one oysters proved to be male on July 24 to August 1, 1923, were isolated in a cage in the sea in the River Blackwater on August 2, 1923. These were tested for individuals carrying young during October 17-22, 1923, and June 7-9, 1924; two oysters carrying larvæ were found in June. The experimental oysters were then transferred to a cage in the sea on the River Yealm near Plymouth. Further testing on August 6-8 yielded two more larva-bearing oysters ; after another short period in the sea another test, made August 26-28, 1924, yielded three more larvigerous oysters, so that during 19247 individuals which were in a male phase in July 1923 had passed into a female phase and produced larvæ. Heavy mortality occurred in the remaining individuals in the winter of 1924-25 and the experiment was closed. 


\section{TABLE II.}

EXPERIMENT 2.

On the Change from Male to Female: West Mersea, R. Blackwater, and R. Yealm near Plymouth.

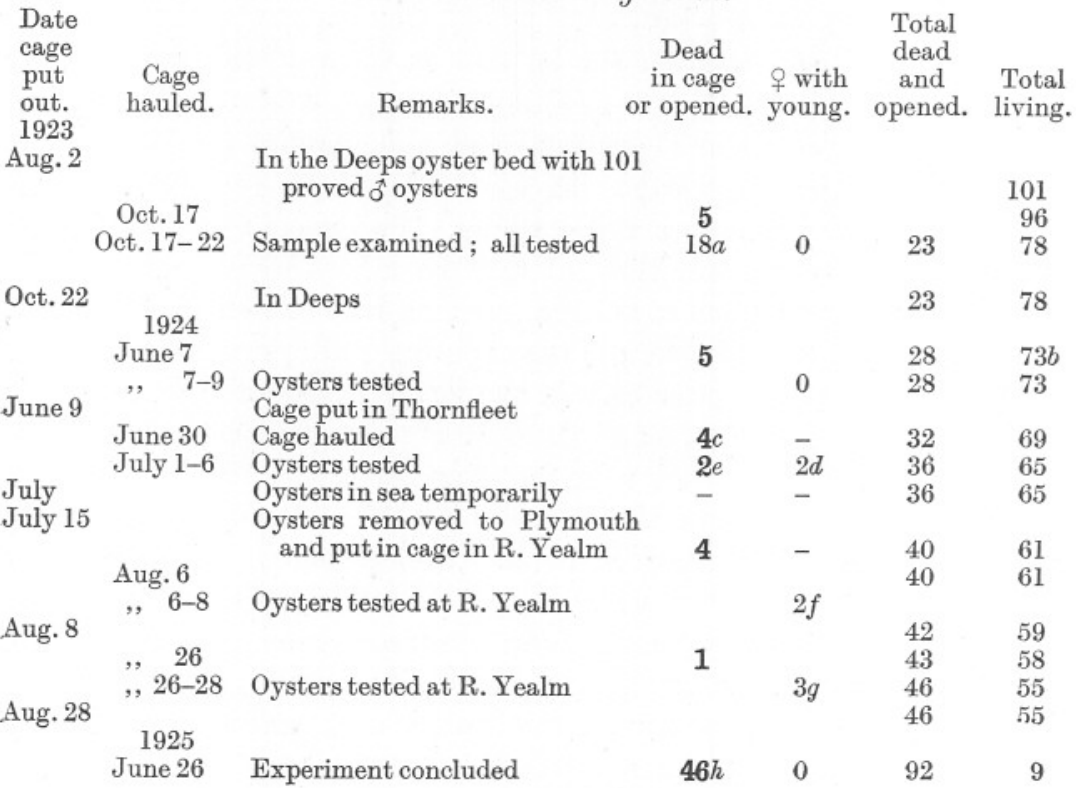

Notes on Table II.

(a) A very good growth of shell (increase in area) was found in all the oysters except 19 on hauling the cage on Oct. 17. The new growth increased the height of the shell from 10 to $18 \mathrm{~mm}$. and is described in 3, p. 382 .

The 18 individuals opened to obtain information on sex-change were found to show the following features on Oct. 18 to 21 .

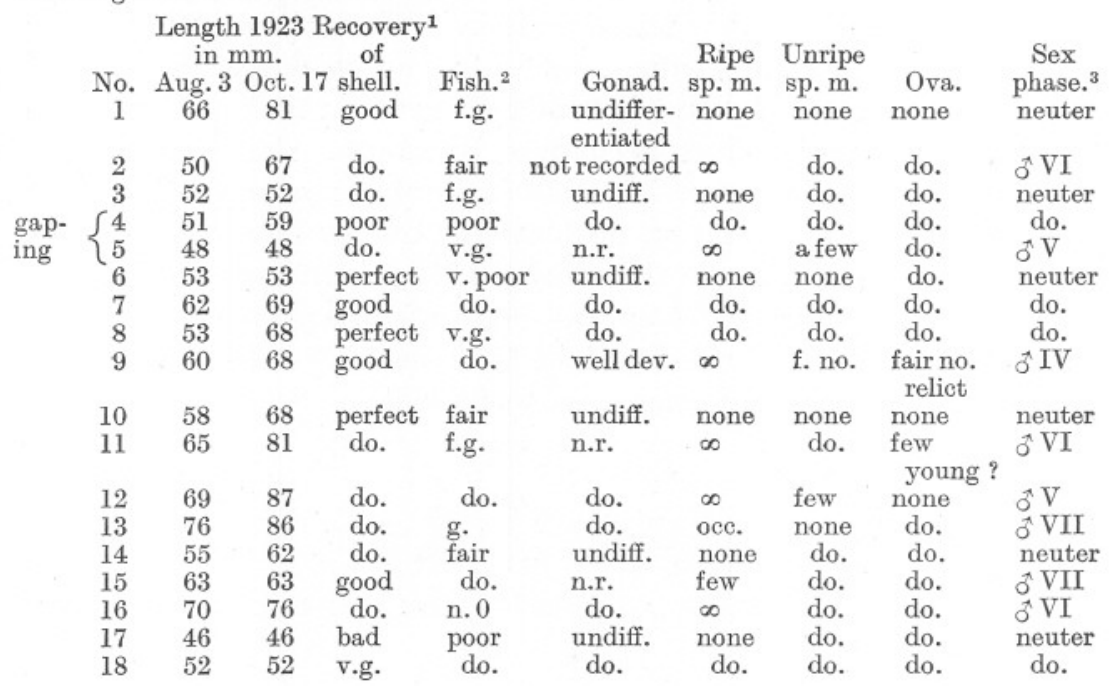


(1) In 15 cases good to perfect recovery from the boring of the shell had been effected by sealing the boring from the inside with a nacreous deposit. In some of these shells, however, infiltration of foreign material had occurred, but this had been isolated on the shell and covered with a deposit of horny or calcareous material. When a poor recovery had been made these infiltrations were often extensive and had resulted in a great strain on the oyster in its effort to recover. In many cases the body showed a distinct scar opposite the boring where the gonad had been tapped.

(2) Under the term "fish" is given the relative condition of nourishment of the body as a whole; it is to be noted that a very good fish may occur in a neuter individual, e.g. No. 8.

(3) In these individuals in early male phases the gonoducts were full of ripe spermmorulæ, in the older phases these were either empty or had few contents. In the neuter cases the ducts were often filled with a milky fluid which contained no sex-elements.

(b) On hauling the cage on June $7,1924,15$ oysters had a new rim of shell-growth 3 to $8 \mathrm{~mm}$., a slight growth only showed in 41 , while no growth had occurred in 17 .

(c) Of the four oysters found dead three had a slight recent growth of shell, 5 to $7 \mathrm{~mm}$. in width, around the edge of the left valve.

(d) One oyster extruded into a dish ciliated larvæ on July 1; the next day the larvæ showed a trace of the larval shell and a tapping of the gonad showed the gonad to be in the $\delta$ phase I with a fair number of unspawned ripe ova. This individual was put in the sea and opened on July 8 when all the larvæ had been extruded. The gonad was found to be in $\hat{o}$ phase III with relict ova in spots. Shell-recovery from the original boring had been perfect. Another individual extruded early embryo on July 6 at 7 p.m.; the next day the embryos at 11 a.m. were in the early heart-shaped stage and the gonad found in of phase II with large sperm-morulæ ca. 110 by $30 \mu$. Recovery from shell-boring had been perfect.

(e) Two gaping individuals were opened; one was neuter with muscle spindles (see 5, p. 48) in the tissues, and the other in ô phase $\mathrm{V}$ with relict ova suggestive of recent femalespawning.

$(f)$ Aug. 8. Black and shelled larvæ were extruded from two individuals whose gonads were in 0 phase IV.

(g) On Aug. 27 one more oyster extruded black-shelled larvæ, and two similar cases were found the next day; all these oysters had passed into $\hat{\sigma}$ phase IV, as was found by retapping the gonad through the old boring.

(h) After the summer of 1924 the cage had to be moved off the dredging ground, and was placed in what was regarded as the most favourable place outside these grounds. The resulting mortality proved that the ground was entirely unsuitable. Periodical freshets and muddy water it is considered accentuated that weakening of the oysters which was no doubt caused by their removal in summer from West Mersea to Plymouth.

\section{Experiment 3. R. Yealm near Plymouth, 1922.}

Ninety-seven oysters proved to be male-from an examination of the gonad made through a boring in the shell-were put in the sea in a cage (see Fig. 7) on the oyster beds in the River Yealm on July 23, 1922. The experimental material consisted of 69 Yealm oysters (which are mostly relaid from Falmouth or Saltash), 20 from the River Blackwater (1922) and 8 Whitstables (1922). The cage was hauled on July 28 and 13 dead were found. A sample of the oysters was brought in for examination and found to be in good condition in good male phases (see note $a$, Table III). The rest were returned to the sea without delay. No further examination was made during the summer. In the spring the cage was visited for the purpose of cleaning and an unexpected accumulation of sticks and mud found in the cage with a concomitant very high mortality among the experimental animals. After a further examination on May 10 the cage was hauled and the oysters brought in on July 7 to be tested for female spawners. Only 19 individuals remained at the beginning of the 
spawning season of 1923 . From July 7 to 10 two individuals were found with young embryos ; one of these yielded but few embryos, it is interesting to note. On July 9, 4 oysters were re-tapped and found to be in male phases; their shells were marked with a distinctive file-mark; 2 others were opened and found to be male and neuter respectively. The cage was hauled again seven weeks later (on August 30), when 4 more dead were found ; the remaining living were again tested for females with young. One such individual extruded numerous black-shelled larvæ and was found to have a filework on its shell. This oyster had therefore passed into a female phase since July 9 ! (See, however, pp. 26 and 42.) On September 4 the gonad of this specimen was again tapped and found to be in male phase V. The survivors, now reduced to 10, were again tested unsuccessfully for larvigerous individuals on September 11 and October 1.

On overhauling the cage on December 8 seven more dead were found and the remaining 3 failed to survive to the breeding season of 1924 .

\section{Summary of Experiment 3.}

Of 97 oysters proved to be male in May-June 1922, 6 were found to be still in male phases in July 1922. No observations were made on the remainder for young-bearing individuals during the breeding season of 1922. Only 19 oysters survived to the winter and 4 more died during the following summer. Tests were made four times during the breeding season of 1923 for young-bearing females and 3 such individuals found. None survived the winter of 1923-24. One oyster carrying larvæ on August 30 had been proved to be male seven weeks earlier, on July 9 .

\section{Summary of Three Experiments on Sex-change in samples of Male Oysters.}

It is advisable to consider the results from these experiments apart from those obtained in a second series which is described later.

When the results of these experiments are brought together as in Table IV below, it is seen that in the second summer of Experiments 2 and $3,10 \%$ to $16 \%$ of the male oysters were detected in the act of carrying young. When it is considered that the breeding season may extend over about three months, and that oysters normally carry their young only from 6 to 14 days, it is highly probable that many of the experimental oysters passed through a female phase undetected. In Experiment 1 it is probable that female phases had just been experienced when the first test was made, and only one other test was made in the second summer. In the third summer of this experiment out of the remaining 6 individuals $3(50 \%)$ were in a female phase.

The evidence obtained from these experiments offers definite proof 


\section{TABLE III.}

\section{EXPERIMENT 3.}

\section{On the Change from Male to Female, R. Yealm near Plymouth.}

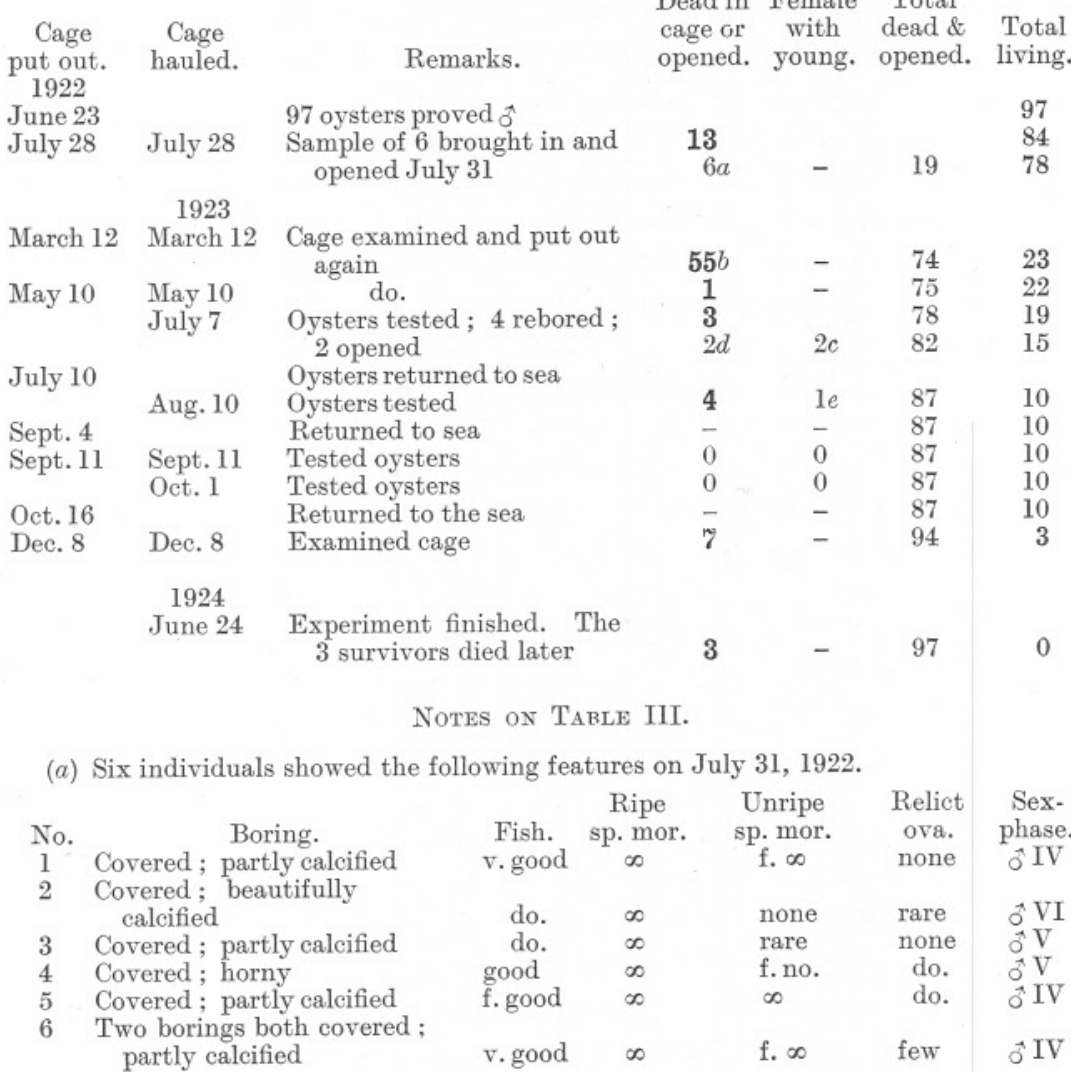

It was noted that sympathetic deposits were present in all cases on the right valve in a position corresponding to that called forth to eover the boring on the left valve : in one case the deposit was noted to be partly calcified.

(b) Heavy mortality had occurred from a great accumulation of sticks and mud.

(c) On July 8 one oyster extruded numerous eggs in late segmentation stages. On July 9 another individual extruded a few eggs also in late segmentation stages ; upon opening this oyster the gonad was found empty : it is presumed that most of the larvæ had been extruded during the hauling process.

$(d)$ The gonad in 4 individuals was re-examined on July 9 by breaking through the old boring; one was in the male phase IV, two in V, and one in VI. The shells of these rebored individuals were marked with a cross by means of a file. Two weakly individuals were opened; one was neuter and the other feebly ô $\mathrm{V}$.

(e) One oyster marked with a cruss extruded on August 31, 1923, numerous blackshelled larvæ ; this oyster had been proved to be male as recently as July 9, 1923 . On September 4 the boring of this oyster was again opened and the gonad tapped, yielding a few ripe sp. mor. and numerous unripe; it had thus attained again the male phase No. III. 
that oysters pass from the male phase into the female phase in significant numbers. As the male oysters were taken at random from a population, it is not known how long such individuals had already existed in the male phase.

Evidence of sex-change from male to female in one summer was obtained in one instance, but such a rapid change was unexpected, and these experiments were not conducted with a view to detecting such a rapid development of the female phase. Evidence of the occurrence of successive male and female phases in successive summers is given by $10 \%$ to $16 \%$ of such changes in Experiments 1 and 2. Fifty per cent of the few survivors (6) in the third summer of Experiment 1 showed passage into the female phase in that summer, but the experimental conditions in this case were such as might be expected to cause delay in egg development.

The severity of the experimental conditions is clearly shown by an average total mortality of $65 \%$ before the advent of the second summer. It is therefore reasonable to suppose that more rapid changes are likely to occur in oysters lying free and naturally on the oyster grounds. The sex-changes observed experimentally are factual, but do not necessarily represent all the changes undergone; neither does the period intervening between successive sex-phases necessarily represent the minimum period; it is highly probable that the normal may be shorter than the observed period. Finally, the absence of records in sex-change in individuals in the second summer may be due either (1) to the detrimental effect of the whole of the experimental conditions (e.g. boring, tapping, muddy environment, repeated exposure in testing) or (2) to the passing of female phases during periods when the oysters were in the sea between successive periods of testing, or (3) to the intervening period being too short to permit the completion of those phases occurring between one egg-bearing phase and the next. The close analysis of young-bearing individuals with regard to the fate of their unspawned ova, given in $\mathbf{6}$ in this Journal, has an important bearing on these experiments. The effect of that analysis is to reveal the possibility that an oyster, presumably proved to be male by a tapping of the gonad, may nevertheless give spurious spawning as a female, if masses of relict ova occur in some other part of the gonad, and if these ova are extruded and fertilised. The possibility of this chancei.e. a second spawning from one batch of eggs - occurring in females which spawned the previous summer is on the evidence available remote; the possibility of the chance occurring in the same season is, however, on the evidence available 2.5 in 100 , but it is advisable to double this number and regard 5 in 100 as possible in the discussion of results. Thus isolated cases of sex-change from male to female in one season-as in the instance noted above-must be regarded as non-significant if female-spawning 
could have occurred in the same breeding season. In the three experiments described above sex-change was rarely investigated in the first summer (see Table IV, below).

\section{Conclusions.}

Under such environmental conditions as occur on English oyster beds, it is found by experiment that oysters proved to be male in a given breeding season change to functional females in significant numbers (10 to $16 \%$ ) in the next breeding season. Under wholly natural conditions it is highly probable that the percentage of males changing into functional females within a period of one year is much greater than that found under experimental conditions.

TABLE IV.

Summary of Three Experiments with Samples of Male Oysters.

\begin{tabular}{|c|c|c|c|c|c|c|c|c|c|}
\hline & $\begin{array}{l}\text { Ist } \\
\text { No. of } \\
\text { oysters. }\end{array}$ & $\begin{array}{l}\text { Summe } \\
\text { No. of } \\
\text { tests } \\
\text { for or's }\end{array}$ & $\begin{array}{l}\text { No. of } \\
\text { 'ts } \\
\text { found }\end{array}$ & $\begin{array}{c}2 \mathrm{n} \\
\text { No. of } \\
\text { survivors. }\end{array}$ & $\begin{array}{l}\text { Summe } \\
\text { No. of } \\
\text { tests } \\
\text { for O's. }\end{array}$ & $\begin{array}{c}\text { O's } \\
\text { found. }\end{array}$ & $\begin{array}{l}\text { No. of } \\
\text { survivors. }\end{array}$ & $\begin{array}{l}\text { Summe } \\
\text { No. of } \\
\text { tests } \\
\text { for O's. }\end{array}$ & $\begin{array}{c}\text { O's } \\
\text { found. }\end{array}$ \\
\hline Expt. 1 & 115 & 0 & 0 & 19 & 2 & 0 & 7 (1 died) & 2 & $3(50 \%)$ \\
\hline & 101 & 0 & 0 & 73 & 4 & $\begin{array}{c}7 \\
\text { (ca } 10 \% \text { ) }\end{array}$ & 9 & 0 & - \\
\hline ," & 97 & $1 / 14^{*}$ & 0 & 19 & 4 & $\begin{array}{c}3 \\
\text { (ca } 16 \% \text { ) }\end{array}$ & nil & - & - \\
\hline
\end{tabular}

\section{TABLE IV $a$.}

\section{Numbers of Original Male-Phases in Experiments} 1,2 AND 3.

\begin{tabular}{|c|c|c|c|c|c|c|c|}
\hline Sex-phase & II & III & IV & V & VI & VII & Totals. \\
\hline Expt. 1 & - & 3 & 36 & 62 & 17 & - & 118 ( 3 died) \\
\hline,,$\quad 2$ & - & 2 & 44 & 34 & 18 & 3 & \\
\hline ", 3 & 1 & 1 & 26 & 54 & 12 & 1 & $95+2$ n.r. $\dagger$ \\
\hline Totals & 1 & 6 & 106 & 150 & 47 & 4 & 314 \\
\hline
\end{tabular}

\section{SERIES B.}

\section{Experiments with Oysters Bearing Young.}

In the following series of experiments individuals found carrying either embryos or larvæ (see p. 15) were isolated in compartments of the cage and returned to the oyster beds to permit normal development of the succeeding sex-phases. It is known that the male phase is assumed immediately after egg-spawning, so that the samples dealt with here would all (but see discussion on p. 26) be males after extruding their

\footnotetext{
* 6 individuals opened July 31. 
larvæ. The precaution was, however, observed in the later experiments of isolating whitesick individuals (i.e. those carrying young embryos or trochophore larvæ) separately from the blacksick ones (i.e. carrying coloured and shelled larvæ) even when both categories of oysters were found with young at the same time. Observations on this material were made as follows :-

(1) At various intervals after immersion in the sea samples were opened and the condition and sex-phases recorded.

(2) At intervals in the breeding season following that in which the experiment was begun, the oysters were taken out of the sea and tested for individuals carrying young at that time. After the test the remaining oysters were returned to the sea and again submitted to the same test after a short interval. Tests and immersions of this kind were repeated as frequently as desirable and possible during the breeding season of successive years. A preliminary account of the earlier experiments was given in $1922(8)$.

\section{Experiment 4. On Females Bearing Young (1922), West Mersea, R. Blackwater.}

The first experiment with oysters carrying young was begun on July 8, 1922 ; details are given in Table V. Seventy-eight individuals found with embryos or larvæ between June 28 and July 7, 1922, were put in the sea in the cage on the Deeps oyster bed (9). The cage was hauled late in the breeding season of 1923, i.e. on July 14, when out of 32 living oysters 1 individual was found carrying young. Two other tests for gravid females were made in July without positive result, before the cage was returned to the sea on August 2. The cage was hauled on October 17 for cleaning and returning on October 22. In June 192419 oysters remained to be tested and 3 of these died in June. Of the 16 remaining specimens (see note $c$, Table V) 1 was found carrying embryos on July $6 ; 2$ were fully ripe females ready to spawn; 1 other was a ripe female dying, while 3 showed evidence of a recent female phase by the presence of relict ova in the gonad; 8 others were good males and the 1 remaining was neuter.

\section{Summary of Experiment 4.}

Of 78 individuals found to be carrying young in July 1922, only 32 survived until July 1923. Tests for gravid oysters were not made at the beginning of the breeding season in 1923, and only 1 oyster with young was found in three tests made in July 1923. No other tests were made until June-July 1924 ; the remaining 16 oysters were opened on July $5-6,1924$, when 1 more gravid and 3 ripe females were found : 3 other 
individuals bore evidence of a recent female phase. In this experiment with individuals which all bore young in 1922, 1 again carried young in 1923 , 1 was found with young in 1924, and 2 or possibly 3 were ready to spawn ova in July 1924. Three others in July 1924 showed evidence of having recently passed through a female phase.

\section{TABLE V.}

\section{EXPERIMENT 4.}

On Females Bearing Young (1922), West Mersea, R. Blackwater.

\begin{tabular}{|c|c|c|c|c|c|c|}
\hline \multirow{2}{*}{$\begin{array}{c}\text { Cage } \\
\text { put out. } \\
1922 \\
\text { July } 8\end{array}$} & $\begin{array}{c}\text { Cage } \\
\text { hauled. }\end{array}$ & Remarks. & $\begin{array}{l}\text { Dead in } \\
\text { cage or } \\
\text { opened. }\end{array}$ & $\begin{array}{l}\text { o with } \\
\text { young. }\end{array}$ & $\begin{array}{l}\text { Total } \\
\text { dead \& } \\
\text { opened. }\end{array}$ & $\begin{array}{l}\text { Total } \\
\text { living. }\end{array}$ \\
\hline & & $\begin{array}{l}\text { Bearing young, June } 28 \text { to } \\
\text { July } 8,1922 \\
\text { Cage put out in Deeps }\end{array}$ & - & - & - & 78 \\
\hline \multirow{3}{*}{ July 15} & $\begin{array}{l}1923 \\
\text { July } 14 \\
\text { July } 14-15\end{array}$ & Tested; 6 opened & $\begin{array}{c}46 \\
5 b\end{array}$ & $1 a$ & 52 & $\begin{array}{l}32 \\
26\end{array}$ \\
\hline & & In sea in creek & - & - & 52 & 26 \\
\hline & $\begin{array}{l}\text { July } 23 \\
\text { July } 31\end{array}$ & $\begin{array}{l}\text { Tested } \\
\text { Tested again }\end{array}$ & 1 & ${ }_{0}^{0}$ & $\begin{array}{l}52 \\
53\end{array}$ & $\begin{array}{l}26 \\
25\end{array}$ \\
\hline Aug. 2 & & In Deeps & $=$ & - & 53 & 25 \\
\hline \multirow{3}{*}{ Oct. 22} & Oct. 17 & & $\begin{array}{l}3 \\
-\end{array}$ & $\begin{array}{l}0 \\
-\end{array}$ & $\begin{array}{l}56 \\
56\end{array}$ & $\begin{array}{l}22 \\
22\end{array}$ \\
\hline & 1924 & & & & & \\
\hline & $\begin{array}{l}\text { June } 7 \\
\text { June 7-9 }\end{array}$ & Tested ; 2 opened & $\begin{array}{l}3 \\
2 c\end{array}$ & $\overline{0}$ & $\begin{array}{l}59 \\
61\end{array}$ & $\begin{array}{l}19 \\
17\end{array}$ \\
\hline \multirow[t]{2}{*}{ June 11} & June & In sea in creek & - & - & 61 & 17 \\
\hline & June 30 & Tested & - & 0 & 61 & 17 \\
\hline \multirow{2}{*}{ July 2} & July 5-6 & $\begin{array}{l}\text { In cage in pit } \\
\text { Tested and opened all : found }\end{array}$ & 3 & - & 64 & 14 \\
\hline & & $\begin{array}{l}4 \text { ripe females and } 3 \text { in } \\
\text { recent o phases } \\
\text { Experiment finisher }\end{array}$ & ${ }_{\text {ed. }}^{13 c}$ & $1 c$ & 78 & 0 \\
\hline
\end{tabular}

(a) One other found greysick July 14, 1923 : opened July 15/23 and found in $\widehat{o}$ phase V with patches of unspawned ova. The shell showed a growth of $12 \mathrm{~mm}$. new shell at the ventral edge.

(b) Five oysters were opened and found as follows :-

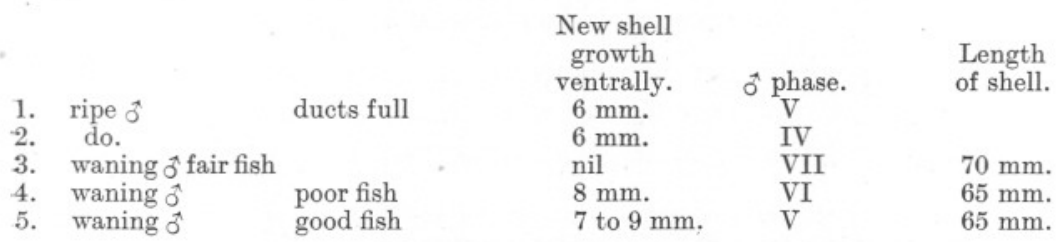

(c) Two oysters found gaping on June 8, 1924, were opened and the 14 remaining opened on July 5-6, 1924. Their condition and sex-characters are as follows : 9 showed slight 
new shell growth from a trace at the exhalant aperture to a rim of $8 \mathrm{~mm}$. of very thin shell at the ventral edge.

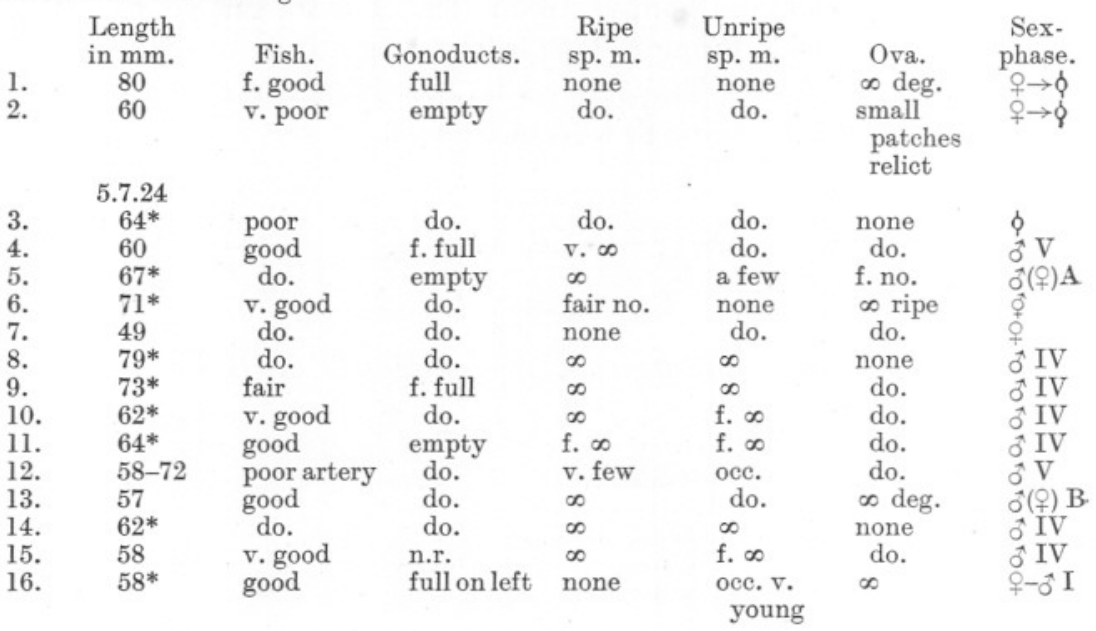

No. 16 extruded embryos in late segmentation stages; when opened it was found to have spawned the eggs from the right side of the body only, the left remaining full of ripe ova. The gonad on the right had a curdled appearance due to many small patches of unspent ova. The individual had spawned incompletely some 12 to 18 hours before examination.

Experiment 5. On Females Bearing Young (1922). Relaid R. Yealm.

During June 16-22, 1922, 27 oysters recently forwarded to Plymouth from Whitstable, Port Navas, and the River Yealm, were found to be carrying embryos (whitesick). These were kept in the tanks at Plymouth until put out in the Yealm cage on June 23. Details of the experiment are given in Table VI, p. 31. The cage was hauled five weeks later when 2 oysters were found dead : 10 were brought back to the Laboratory and opened for information regarding development of gonad; 1 of these was found blacksick, carrying a large number of larvæ.

On March 12, 1923, the cage was hauled for cleaning; 10 individuals were found dead. The remainder were tested four times during the breeding season of 1923, but none found with either embryos or larvæ. None of these survived to the following breeding season.

\section{Summary of Experiment 5.}

Ten of the orginal 27 oysters used in the experiment were opened after being in the sea five weeks. One of these was found blacksick and had either retained its larvæ or spawned a second time from the eggs matured

* Nine individuals showed a slight new growth of shell, June 7-9, consisting of very thin shoot varying from a trace at the exhalant aperture to a rim of about 3 to $8 \mathrm{~mm}$. at the ventral edge. The gaper, No. 1, and several others had grown good shell-shoots in the autumn of 1923 . 
in June. Ten of the 15 remaining oysters died during the following winter and none of the survivors was found in spawn during four tests made in the succeeding breeding season.

\section{TABLE VI.}

\section{EXPERIMENT 5.}

On Females Bearing Young (1922), R. Yealm near Plymouth.

\begin{tabular}{|c|c|c|c|c|c|c|}
\hline $\begin{array}{l}\text { Cage } \\
\text { put out. }\end{array}$ & $\begin{array}{c}\text { Cage } \\
\text { hauled. } \\
1922\end{array}$ & Remarks. & $\begin{array}{l}\text { Dead in } \\
\text { cage or } \\
\text { opened. }\end{array}$ & $\begin{array}{l}\text { 우 with } \\
\text { young. }\end{array}$ & $\begin{array}{c}\text { Total } \\
\text { dead \& } \\
\text { opened. }\end{array}$ & $\begin{array}{l}\text { Total } \\
\text { living. }\end{array}$ \\
\hline June 23 & July 28 & $\begin{array}{l}\text { Tests made } \\
10 \text { opened and examined }\end{array}$ & $\stackrel{2}{10 a}$ & $\overline{1}$ & $\overline{12}$ & $\begin{array}{l}27 \\
25 \\
15\end{array}$ \\
\hline & 1923 & & & & & \\
\hline $\begin{array}{l}\text { March } 12 \\
\text { May } 10\end{array}$ & $\begin{array}{l}\text { March } 12 \\
\text { May } 10\end{array}$ & & $\begin{array}{r}10 \\
0\end{array}$ & $\begin{array}{l}- \\
-\end{array}$ & $\begin{array}{r}22 \\
-\end{array}$ & $\begin{array}{l}5 \\
5\end{array}$ \\
\hline Jplv 10 & July 7 & Tests made & $\begin{array}{l}0 \\
0\end{array}$ & 0 & - & 5 \\
\hline Sept, 4 & Aug. 30 & do. & $\begin{array}{l}1 \\
0\end{array}$ & $\begin{array}{l}0 \\
-\end{array}$ & $\begin{array}{r}23 \\
-\end{array}$ & $\begin{array}{l}4 \\
4\end{array}$ \\
\hline Sept. 15 & Sept. 11 & do. & 0 & 0 & - & 4 \\
\hline Oct. 16 & Oct. 1 & do. & $\begin{array}{l}0 \\
0 \\
\text { ? }\end{array}$ & $\begin{array}{l}0 \\
- \\
-\end{array}$ & $\overline{-}$ & $\begin{array}{l}4 \\
4 \\
9\end{array}$ \\
\hline 1924 & June 24 & Experiment ended & $\tilde{2}$ & 0 & 27 & 0 \\
\hline
\end{tabular}

(a) All these individuals were in either No. V or No. VI male phases.

See 1, Table IX, lots 92 and 93 , for details of 8 of these oysters.

\section{Experiment 6. On Females Bearing Young (1923), W. Mersea, R. Blackwater.}

In this experiment $29 \mathrm{O}$. edulis carrying either embryos or young were detected between July 14 and August 2, 1923, at West Mersea and returned to the sea in Deeps in the cage on August 2, 1923. Details of the experiment are given in Table VII, p. 32. After a cleaning inspection in October 1923 the cage was hauled again on June 7, 1924, when 23 living oysters remained. A test made in June revealed no individuals bearing young, but early in July 2 such individuals were found. The survivors were opened on July 8, eleven months after the experiment began, when 1 more individual was found with embryos, 1 ripe female was ready to spawn, and 3 contained ova which were regarded as unspent from a previous female phase.

\section{Summary of Experiment 6.}

In 19243 oysters which bore young in 1923 were again found in good female phases ( 2 with young and 1 full of ripe ova) in July. This 
experiment was begun with 29 individuals, of which 20 survived to be examined in the following breeding season.

\section{TABLE VII.}

Experiment 6.

On Females Bearing Young (1923), West Mersea, R. Blackwater.

\begin{tabular}{|c|c|c|c|c|c|c|}
\hline 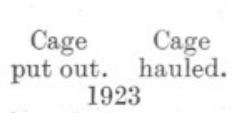 & Remarks. & $\begin{array}{l}\text { Dead } \\
\text { in } \\
\text { cage and } \\
\text { opened. }\end{array}$ & Ripe 우. & $\begin{array}{l}\text { ㅇ with } \\
\text { young. }\end{array}$ & $\begin{array}{l}\text { Total } \\
\text { dead \& } \\
\text { opened. }\end{array}$ & $\begin{array}{l}\text { Total } \\
\text { living }\end{array}$ \\
\hline Aug. 2 & In Deeps & & & & & 29 \\
\hline Oct. 17 & & 1 & & 0 & 1 & 28 \\
\hline Oct. 20 & Opened 2 & $2 a$ & & - & 3 & 26 \\
\hline Oct. 22 & & - & & - & 3 & 26 \\
\hline 1924 & & & & & & \\
\hline June 7 & & 3 & & & 6 & 23 \\
\hline June 8 & 2 gaping; opened & $2 b$ & & 0 & 8 & 21 \\
\hline June 9 & In Thornfleet & - & - & - & 8 & 21 \\
\hline June 30 & & 3 & - & - & 11 & $18 c$ \\
\hline July 1 & 1 gaping; opened & 1 & - & - & 12 & 17 \\
\hline July 1-2 & Tests made & - & - & 0 & 12 & 17 \\
\hline July 5 & $\begin{array}{l}\text { In cage in pit } \\
\text { Tests made }\end{array}$ & 0 & - & $2 d$ & 14 & 15 \\
\hline July 8 & Remainder opened & 15 & 1 & 1 & 29 & 0 \\
\hline
\end{tabular}

Experiment ended.

$(a),(b)$, and $(c)$ are described in 1, pp. 1027-8, Table IX, lots 107, 108, and 110 .

(c) Amongst the 18 oysters opened and examined from July 1 to 8,13 were in good male phases, two were found with numerous embryos or larvæ, one was a ripe female, and three others retained in their gonad ova which appeared to be degenerating and may be regarded as relict from the last female spawning.

(d) One of these individuals was a doubtful spawner : a few black larvæ were discovered on the glass plate below the oyster, but none were found in the mantle cavity.

\section{Experiment 7. On Females Bearing Young (1923), R. Yealm, near Plymouth.}

Experiment 7 was begun with 21 oysters received at Plymouth from various oyster grounds during June, July, and August 1923, and proved to be carrying young. Most of them were in the whitesick stage on arrival, but a few of the later ones were blacksick or bore shelled larvæ. Eighteen were sent from Whitstable, 2 from Port Navas, and 1 from West Mersea ; whitesick individuals were received from the three localities between June 18 and 21. After being proved these oysters were kept in the tanks in the Plymouth Laboratory until put out in the experimental cage on August 30 .

The cage was hauled on October 2 and a sample of 8 brought back to the Laboratory for the purpose of photographing the new good shellgrowth made by the experimental oysters (see note $a$, Table VIII). When the oysters were again examined on June 24, 1924, 19 survivors 
were found and 1 extruded numerous embryos. Two more were carrying abundant young at another test made July 15-16, and 1 more was found at the fourth test made on August 8. Although these oysters had been relaid from various parts of England, 17 out of 21 survived a winter and the following summer. Only 1, however, survived the second winter.

\section{Summary of Experiment 7.}

Of 21 oysters carrying young in 1923 and relaid in the River Yealm on August 30, 1923, 4 were found again with young during the summer of 1924 .

\section{TABLE VIII.}

\section{EXPERIMENT 7.}

On Females Bearing Young (1923), R. Yealm near Plymouth.

\begin{tabular}{|c|c|c|c|c|c|c|}
\hline $\begin{array}{l}\text { Cage } \\
\text { put out. }\end{array}$ & $\begin{array}{r}\text { Cage } \\
\text { hauled. } \\
1923\end{array}$ & Remarks. & Dead. & $\begin{array}{l}\text { + with } \\
\text { young. }\end{array}$ & $\begin{array}{c}\text { Total } \\
\text { dead or } \\
\text { opened. }\end{array}$ & $\begin{array}{l}\text { Total } \\
\text { living. }\end{array}$ \\
\hline Aug. 30 & & On the Yealm oyster beds & - & & & 21 \\
\hline & Sept. 15 & Tests made & 0 & 0 & 0 & 21 \\
\hline Oct. 16 & Oet. $2-16$ & $\begin{array}{l}\text { Sample of } 8 \text { brought in. } \\
\text { Tests made; shell-growth }\end{array}$ & & & & \\
\hline \multirow{3}{*}{ Dec. 8} & & $\operatorname{good}(a)$ & 0 & 0 & 0 & 21 \\
\hline & Dec. 8 & Cage overhauled & 0 & - & 0 & 21 \\
\hline & 1924 & & & & & \\
\hline \multirow[t]{2}{*}{ June 26} & June 23 & Tests made & 2 & $1 b$ & 2 & $\begin{array}{l}18+1^{*} \\
18+1\end{array}$ \\
\hline & July $15-16$ & Tests made & 0 & $2 c$ & 2 & $16+3$ \\
\hline July 18 & & & 1 & - & 3 & $15+3$ \\
\hline \multirow[t]{2}{*}{ Aug. 8} & Aug. 6-8 & Tests made & 0 & $1 d$ & 3 & $15+3$ \\
\hline & Aug. 26 & Tests made & 0 & $\begin{array}{l}0 \\
0\end{array}$ & 3 & $15+3$ \\
\hline \multirow{2}{*}{ Aug. 28} & 1925 & & 1 & & & $14+3$ \\
\hline & June 26 & Experiment ended & $13+3$ & 0 & 20 & 1 \\
\hline
\end{tabular}

(a) A photograph of these 8 oysters is given in 3, p. 381, with a description on p. 382 . The new shell-growth varied from a few to $8 \mathrm{~mm}$. in extent.

(b) This oyster extruded numerous embryos on June 24, in late segmentation stages, and was traced and put back in the cage. On July 16 the gonad was tapped and found to be in male phase $V$.

(c) One individual extruded numerous embryos at the instant of developing cilia and acquired a good ring of cilia by July 18. The gonad was retapped on July 17, and found to be in male phase I.

The other extruded numerous embryos in a similar stage; these also developed cilia and could swim on July 17 . The gonad was in male phase I on July 18 and contained some unspent ova. Both oysters were traced and put back in the eage in the sea. On August 28 both borings were found to have been repaired. These oysters died during the following winter.

(d) One extruded numerous slate-coloured larvæ with shells 180 to $190 \mu$ : on opening it was found to have a gonad in male phase III and to be completely spent (as a female).

* Individuals which spawned again in 1924 .

NEW SERIES-VOL. XIX. NO. 1. AUGUST, 1933. 
Experiment 8. On Females Blacksick, July 1924, West Mersea, R. Blackwater.

From July 1 to 9 , 1924, 60 blacksick oysters were proved and put out in the cage in Deeps on July 9. On July 2, 1925, the cage was hauled and 21 dead individuals found. The 39 living were tested unsuccessfully, July $2-5$, for sick individuals and were put back in the sea from July 5 to July 13. On the latter date they were taken out of the sea and all opened during the following two days. The characters of these oysters at this time are given in detail in 1, p. 1028, lot III, and are summarised as follows :-

\section{TABLE IX.}

$\begin{array}{cr}1925 & \text { No. } \\ \text { July 13-15 } & 4 \\ & 1 \\ & 12 \\ & 10 \\ & 8 \\ & 3 \\ & 1 \\ & \\ & 39\end{array}$

Sex-condition.

Carrying embryos or larvæ Ripe female ready to spawn Male phase IV , , , V

$, \quad, \quad$ VI

$, \quad, \quad$ VII

macerating
Fish. poor to fair* very good fair to good poor to good poor to good poor to good

Experiment 9. On Females Whitesick, June-July 1924, West Mersea, R. Blackwater.

From July 10-13, 1924, 72 oysters were proved to be whitesick and stored in a pit. On July 8-9, 3 more whitesick individuals were found and all were put in the cage in the sea in Deeps on July 9, 1924, at the same time as those used in Experiment 8.

On hauling the cage on July 2, 1925, 49 living oysters were found. These were tested July 2-3 and 1 found blacksick; 4 found gaping were opened and examined. From July 5-13 the sample was re-examined, when one was found dead; the remainder were tested and opened July 13-16. The details of the examination are given in 1, p. 1029, lot 112, and may be summarised as follows :-

* Two had retained a few unspent eggs in the gonad. Only one individual among the 33 male phases had eggs in the gonad; this individual had a gonad of curdley appearance, and the eggs were regarded as relict from a previous female phase. The cage was hauled after the beginning of the breeding season, it is to be noted, when early female spawners may already have extruded their larvæ. 
TABLE X.

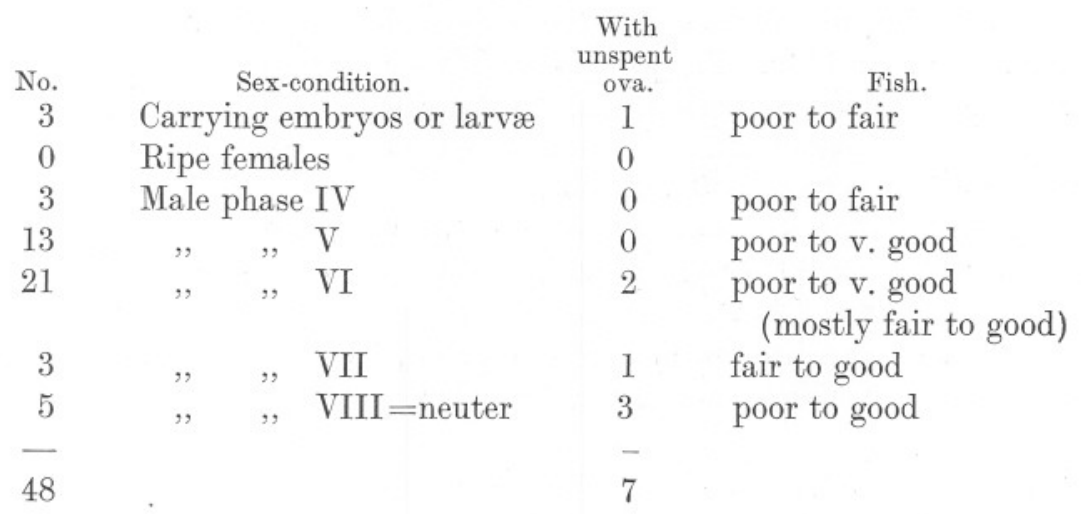

In this experiment six individuals in non-functional female phases had retained few or many eggs from a previous female phase. As in the case of Experiment 8 some individuals may have spawned and evacuated their young in the early part of the breeding season of 1925, before the cage was hauled.

Experiment 10. On Females (West Mersea and Fal Estuary) Blacksick, July 1925, West Mersea, R. Blackwater.

A. During July 1925 a collection was made of 38 blacksick oysters from dredgings from the West Mersea beds. These were put out in the cage in Deeps on July 21, and hauled July 3, 1926. Twenty-eight individuals were found alive. The sample was opened at once and examined for sex-condition. Particulars are given in 1, p. 1030, lot 113A. Two were functional females, 1 of these being hermaphrodite but full of ripe eggs ; the remaining individuals were mostly good males in good condition.

B. Sixteen blacksick oysters sent on from the Fal Estuary beds in July 1925 were treated in the same way as the preceding sample A. When the 7 survivors were examined on July 3, 1926, 1 individual was found to be hermaphrodite with abundant ripe ova. This type of individual is regarded as a functional female. Five others were in good condition as ripe or ripening males and 1 was neuter in poor condition.

\section{Experiment 11. On Females (West Mersea and Fal Estuary) Whitesick, July 1925, West Mersea, R. Blackwater.}

A. During July 1925, 48 whitesick oysters were found amongst samples dredged at West Mersea, and put in the cage in Deeps on July 21, 1925. When the cage was hauled on July $3,1926,41$ oysters were found alive 
and tested July 3-5. None were then found in spawn. On July 7 the whole sample was opened and the sex-condition noted as is given in 1, p. 1030, lot 113в. Three individuals were found carrying young, 3 were ripe or ripening females, and 1 was a ripe female with sperm in the gonad ; the remainder of the sample were males in various phases except for 3 weakly and neuter individuals.

B. Twenty-one whitesick oysters sent to West Mersea from the Fal Estuary in July 1925 were treated in the same way as the sample A described above. When examined on July 3, 1925, of the surviving 6 oysters 1 was a ripe female ready to spawn, 4 were ripe males in good or very good condition, and 1 was a weakly neuter.

\section{Experiment 12. On Females Bearing Young 1926, Truro Beds, Fal Estuary.}

A. In this experiment 61 Fal Estuary oysters found with black or grey-shelled larvæ in July 1926 were put out in a new cage in Trelissick Reach on July 29, 1926. This sample was hauled and examined on September 29, 1926, to obtain information on gonad changes in the same breeding season as the oysters were found in spawn. The details of this sample are given in 1, pp. 1031-2, lot $114 \mathrm{~A}$, and may be summarised as follows :-

The sample consisted of 43 with normal shells, of which 2 died, and 18 with dumpy shells (for definition see \%, p. 200), of which 1 died.

\section{TABLE XI.}

Category.

\begin{tabular}{ccrc}
\multicolumn{3}{c}{ Normal. } & \multicolumn{3}{c}{ Dumpy. } \\
No. & With relict ova. & No. & With relict ova. \\
1 Bl. & 0 & 1 & 0 \\
0 & 0 & 0 & 0 \\
0 & 0 & 0 & 0 \\
2 & 0 & 1 & 0 \\
$17 *$ & 1 & 11 & 0 \\
9 & 0 & 2 & 0 \\
10 & 1 & 2 & 0 \\
2 & 0 & 0 & 0 \\
- & - & - & - \\
41 & 2 & 17 & 0
\end{tabular}

B. Three whitesick oysters were put out and hauled with sample A noted above. One died; the two remaining were in male phases IV

\footnotetext{
* One of these might have had very young ova, but microscopic sections are required for certainty in identification.
} 
and V respectively on September 29, 1926, and neither had unspent ova in the gonad (see loc. cit., lot 114в).

C. A sample of 28 blacksick individuals was also put out in another cage moored to the Poles Rocks, Fal Estuary. These were put out on July 21, 1926, and examined for general gonad condition on September 30, 1926. Three died. The details of the living ones are given in 1, p. 1032, lot $115 \mathrm{~A}$, and may be summarised as follows :-

\section{TABLE XII.}

\begin{tabular}{|c|c|c|c|c|}
\hline \multirow[t]{2}{*}{ Category. } & \multicolumn{2}{|c|}{$\begin{array}{l}\text { Normal. } \\
\text { No. }\end{array}$} & \multicolumn{2}{|c|}{$\begin{array}{l}\text { Dumpy. } \\
\text { No. }\end{array}$} \\
\hline & c. & $\mathrm{D}$ & $\mathrm{C}$ & $\mathrm{D}$ \\
\hline o's with young & $2 \S$ & Wh) & 0 & \\
\hline ripe females & 0 & & 0 & \\
\hline ô phase IV & 1 & & 0 & \\
\hline,$\quad \mathrm{V}$ & 2 & & 1 & 1 \\
\hline,$\quad$ VI & $8 \S$ & $7 \S$ & 1 & 1 \\
\hline, VII & $5^{*}$ & 2 & $4 \dagger$ & 1 \\
\hline , VIII & 1 & $3+$ & 0 & \\
\hline & - & - & - & - \\
\hline Sample $\mathrm{C}$ totals & 19 & & 6 & \\
\hline Sample D , , & & 12 & & 3 \\
\hline
\end{tabular}

D. In the cage moored to Poles Rocks on July 21, 1926, were also isolated 15 oysters found whitesick during July 1926. These all survived and were examined on September 30, 1926. Details of their general condition are given in $1, \mathrm{p} .1033$, lot $115 \mathrm{~B}$, and are summarised under D in the table given above.

\section{Experiment 13. On Females Bearing Young, 1926, West Mersea, R. Blackwater.}

In earlier experiments females carrying spawn have been examined after isolation in the sea for twelve months or more, or in the case of the last experiment after about two months. In this experiment 45 blacksick and 66 whitesick oysters were collected and put out in the sea at West Mersea on July 14, 1926, and examined just before the beginning of the breeding season in 1927, namely on May 27, the cage having been hauled

\footnotetext{
* One with numerous young ova.

$\dagger$ Two with doubtful young ova.

One with doubtful young ova.

$\S$ One with unspent ova, probably many young relict ova in the $q$ with larvæ.
} 
on May 26. The details are given in Tables XIV and XV, pp. 39 and 40 , and may be summarised as follows :-

\section{TABLE XIII.}

Category.

q's with young

ripening and ripe + phases

young ơ's

ô (ㅇ) B

neuter

A. Blacksick, 1926.

B.

ripening and ripe $\widehat{0}$ 's

young and developing 0 's died

$\begin{array}{lr}0 & 0 \\ 8 & 5 \\ 1 & 1 \\ 2 & 1 \\ 3 & 0 \\ 21 & 39 \\ 3 & 18 \\ 7 & 2 \\ - & - \\ 45 & 66 \\ & \\ \text { FEMALES AND } & \text { RIPE } \\ \text { XES. } & \end{array}$

Experiment 14. On the Isolation in the Sea of Ripe Females, West Mersea, R. Blackwater, 1923.

When boring oysters for the purpose of finding males in July 1923, 12 ripe female individuals were discovered. These were returned to the sea in a whelk-pot hung over the stern of a vessel in Thornfleet until October 1923, when they were hauled and opened and examined on October 29. Eight of them were found to have made good shellgrowth, of which a photograph is shown in 3, Fig. 6, p. 379. The sexphases were as follows :-

\section{TABLE XVI.}

$\begin{array}{ccccc}\text { Male Phases. } & \text { V } & \text { VI } & \text { VII } & \text { VIII } \\ \text { Total } 12 \text {, } 8 \text { with relict ova } & 2 & 5 & 1 & 4 \\ \text { ", } & 2 & 1 & 1 & 4\end{array}$

All the individuals had spawned, but eight showed indications of a recent female phase in the presence of relict ova in the gonad.

Experiment 15. On the Isolation in the Sea of Hermaphrodites, West Mersea, R. Blackwater, 1923.

Four hermaphroditic oysters were found at the same time and in the same way as the females mentioned in Experiment 14. These were also isolated in Thornfleet and examined on October 29, 1923. Three had 


\section{TABLE XIV.}

\section{EXPERIMENT 13, A.}

On Females Blacksick, West Mersea, July 1926, examined May 27, 1927.

\begin{tabular}{|c|c|c|}
\hline No. & $\begin{array}{l}\text { Condition } \\
\text { of Fish. }\end{array}$ & $\begin{array}{l}\text { Appearance }{ }^{1} \\
\text { of gonad. }\end{array}$ \\
\hline 1 & f. & sq. \& trs.retic. \\
\hline 2. & f. & - \\
\hline 3. & f.g. & ram. A trs. retic. \\
\hline $\begin{array}{l}4 . \\
5 .\end{array}$ & f. to $\mathrm{p} \cdot{ }^{4}$ & $\begin{array}{l}\text { white nf. }\left(\delta^{\prime}\right) \\
\text { trs. retic. ; st. B }\end{array}$ \\
\hline 6. & f. 45 & sq. \& trs. \\
\hline 7. & v.g. ${ }^{6}$ & ram. A op. retic. \\
\hline 8. & f.g. & - \\
\hline $\begin{aligned} 9 . & \\
10 . & .\end{aligned}$ & $\begin{array}{l}\text { f. to p. } \\
\text { f.g. }\end{array}$ & ram. A trs, retic. wh. \\
\hline 11. & g. & - \\
\hline 12. & g. & - \\
\hline 13. & g. & - \\
\hline 14. & g. & 一 \\
\hline 15. & g. & so. \& trs, st. \\
\hline $\begin{array}{l}16 . \\
17 .\end{array}$ & $\begin{array}{l}\text { g. } \\
\text { v.g. }\end{array}$ & $\begin{array}{l}\text { sq. \& trs. st. } \\
\text { white nf. }\left(\sigma^{*}\right) q^{+} \text {q }\end{array}$ \\
\hline $\begin{array}{l}17 . \\
18 .\end{array}$ & $\begin{array}{l}\text { v.g. } \\
\text { g. }\end{array}$ & white nf. (ठ) \\
\hline 19. & f.g. & - \\
\hline 20. & g. 7 & - \\
\hline 21. & f. to $\mathrm{D}^{7}$ & G.D. st. A-ram. A \\
\hline 23. & $\begin{array}{l}\text { g. } \\
\text { v.p. }{ }^{7}\end{array}$ & $\begin{array}{l}\text { sq. \& trs., honeyc. \& retic. } \\
\text { watery }\end{array}$ \\
\hline 24. & f. & sq. \& trs. honeyc. retic. \\
\hline 25. & f.g. & - \\
\hline 26. & g. & - \\
\hline 27. & f. & white $\overline{f f} .(\hat{0}) \emptyset 0$ \\
\hline $\begin{array}{l}28 . \\
29 .\end{array}$ & v. & 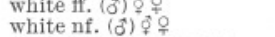 \\
\hline 30 . & $\mathrm{f}^{6}$ & sq. \& trs. retic. honeyc. \\
\hline 31. & g. ${ }^{6}$ & ram. A wh. retic. ơ? \\
\hline 32. & f.g. & - \\
\hline 33. & v.g. & neth ne $(\hat{)}) * 0$ \\
\hline $\begin{array}{l}34 . \\
35\end{array}$ & g. ${ }^{6}$ & wh. retic. nf. $(\hat{0})+\%$ \\
\hline $\begin{array}{l}35 . \\
36 .\end{array}$ & $\begin{array}{l}\text { v.g. } \\
\text { v.g. }\end{array}$ & $\begin{array}{l}\text { ram. A opaque } \\
\text { ram. }\end{array}$ \\
\hline 37. & g. ${ }^{6}$ & ram. A wh. \& trs retic. \\
\hline 38. & g. & - \\
\hline
\end{tabular}

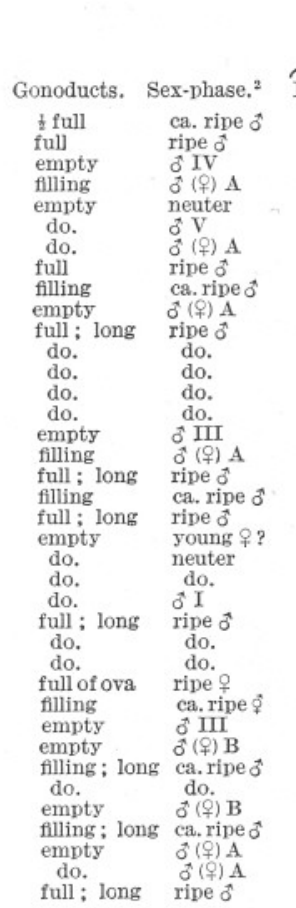

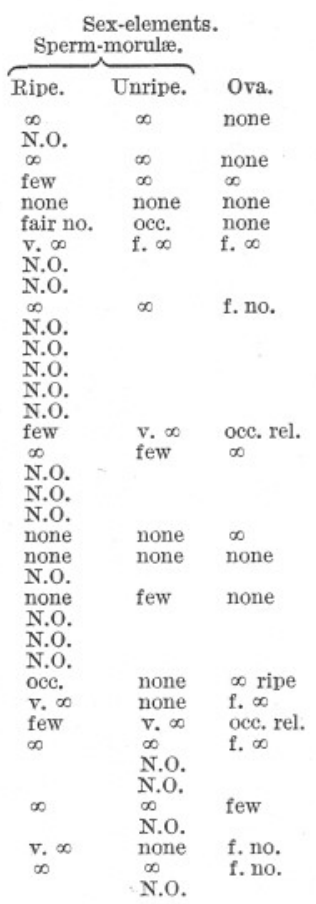

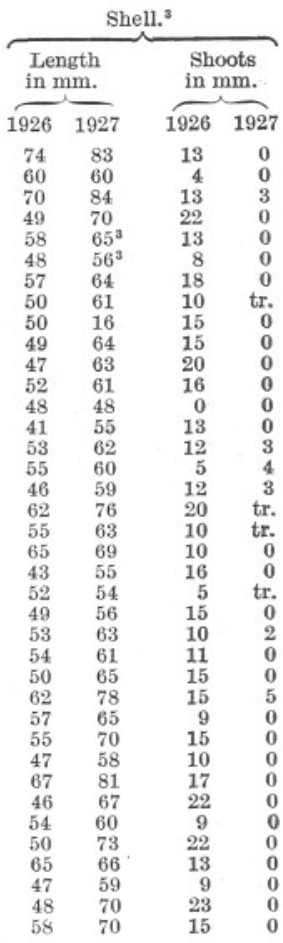

\section{Notes on Table XIV.}

1 The abbreviations usted to denote the naked eye appearance of the gonad will be amplifled and discussed in a later communica. tion on a seasonal study of an oyster population.

2 For a description of sex-phases, see 1, pp. 975 and 981 .

3 The comparison in this sample and that noted in Table XV between the growth of large shell-shoots in the autumn of 1926 and the slight, or absence of such growth in the spring of 1927, is especially interesting (see $3, p .377$ ). The length of the shell is measured antero-posteriorly and is on the average about the same as the height measured dorso-ventrally; the shoot is measured in the midventral line, where it is usually largest, tapering off anteriorly and posteriorly.

${ }^{4}$ Shells chambered indicating constitutional trouble of some kind, at some unknown period.

${ }_{5}^{5}$ Muscle spindles (see 5, p. 48) present in the visceral mass.

6 An appearance of abundant food reserve material is noted in correlation with the presence of degenerating and/or developing ova (see 1, p. 976).

7 Mantle cavity choked with mud; this fact in correlation with the poor condition of the flsh indicates permanent weakness. Abbreviations :
$\mathrm{f} .=$ fair or fairly.
g. $=$ good.
$\mathrm{v} .=$ very,
$\mathrm{p},=$ poor
$\infty=$ numerous. $\quad$ no. $=$ number. $\quad$ tr. $=$ trace.

G.D. $=$ Gonad developing.

G.L.D. = Gonad little or slightly developed.

G.M.D. = Gonad mediumly developed.

G.W.D. $=$ Gonad well developed.

N.O. $=$ not observed, as experience taught that microscopic examination is not necessary in such cases, General.

The gills in this sample were mostly coloured slightly green and were thus on the point of the seasonal change from the winter state of being coloured a ferrous-sulphate green to the summer state of white gill. Some gills were brown, i.e. nos. 3, 4, 9, 17, 19, 22, 23,25 , and 38 . 


\section{TABLE XV.*}

\section{Experiment 13, B.}

On Females Whitesick, West Mersea, July 1926, examined May 27-28, 1927.

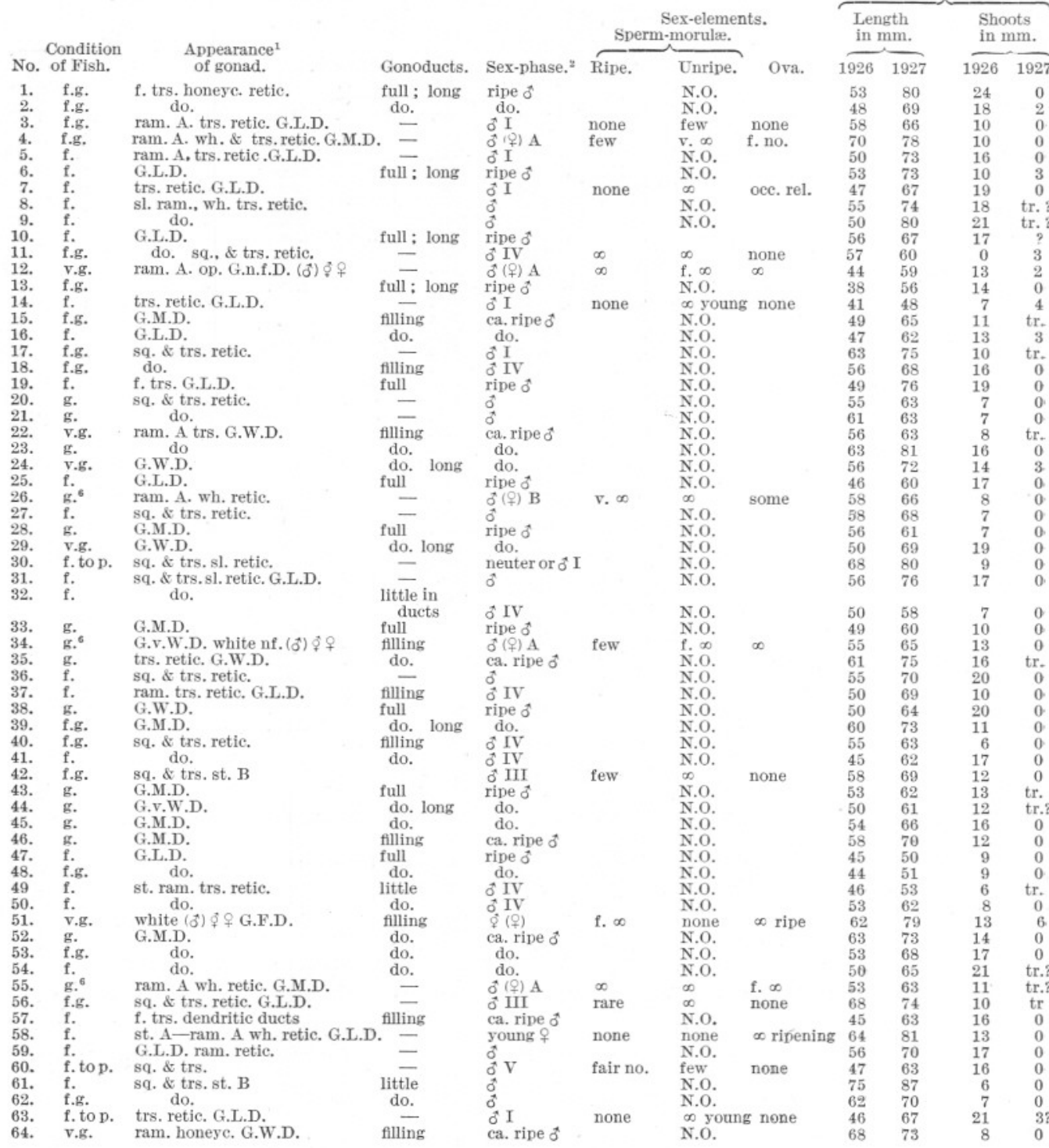

* See notes to Table XIV for explanatory remarks. In this sample the gills were mostly slightly green : in 11 individuals they were brown. 
spawned all or nearly all the ova, but 1 had spawned its ova only partially. The latter was in sex-phase VII with relict ova, and with two others, which were in sex-phases VI and VII, had made a perfect recovery from the boring. The fourth had made a very bad recovery from the operation and its gonad had no sex-elements.

\section{Summary and Discussion of Experiments on Isolating Oysters. Carrying Young (Series B) and on those with Ripe Eggs (Series C).}

The results obtained in the set of experiments with oysters bearing young are summarised in Tables XVII A and B, p. 44, and XVIII, pp. 46-47.

From Table XVII B it is seen that at the end of the same breeding: season as that in which the experimental individuals were found, i.e. the lst summer, a proportion as high as $3.4 \%$ were again detected bearing: young. In the second summer about $5 \%$ were found again with young and an additional $7 \%$ were ready to spawn as females. Among the small number of individuals surviving to the third summer of the experiments. about $5 \%$ were again found with young and at least an additional $15 \%$. ready to spawn as females. Among all the experimental oysters about $11 \%$ were discovered again in ripe female functioning stages.

It may be presumed that all female-functioning oysters revert again to the female phase at some time after passing through an intermediate male (and possibly a neuter) phase. Hence the gross percentage of reversion to the ripe female phase found is small except in the experiment which ran into the third summer. There can be no doubt that the actual reversions occurring were much greater in number than found from the following considerations :-

(1) In several experiments (e.g. 10 and 11) only one test was made during the breeding season, so that only those females existing as such at that time of the season were detectable. It is known that female phases may develop throughout the extent of the breeding season, although on the beds in the River Blackwater a maximum of spawning usually occurs about July.

(2) In some experiments tests were not made until some weeks after the opening of the spawning season, hence early spawners may have extruded larvæ before examination.

(3) In experiments 7, 5, and 4, tests were made only for detecting females with young in the second summer of the experiments. In these cases only those females actually carrying young at the time of examination could be detected.

(4) When tests were made frequently, as in experiments 7, 5, and 4, young-bearing phases may nevertheless have passed undetected in the sea in the intervals of testing. 
(5) The presence of ova-recognisable in most cases as relict from a recent spawning - in the gonad of eleven individuals either male or neuter examined in the second summer of the experiments, and of two other such individuals amongst the few surviving into the third summer, affords evidence of the occurrence of the undetected production of larvæ among the experimental oysters.

Thus the reversions found by experiment in all cases can certainly be regarded as smaller than actual.

On the oyster beds it may reasonably be expected that the reversions to the young-bearing stage would be greater than those actually occurring under experimental conditions, the detrimental effect of which is demonstrated by the known heavy mortality. The attainment of the functional female phase may be postulated to be dependent upon a period of anabolic metabolism, and the building up of good reserves would undoubtedly be delayed or depressed by those detrimental conditions ancillary to the experiments already referred to on p. 26. Thus reversion to the female phase on the oyster grounds may reasonably be expected to be not only greater than that found in the experiments, but also greater than that actually occurring in them.

Although a greater percentage of reversions to the young-bearing phase may occur naturally on the beds than in the experiments, there are indications that a small proportion of the spawning taking place under experimental conditions may be a result of these conditions. It is clear that a correct estimation of any error introduced by the conditions of the experiment is of the greatest importance in assessing the results.

During the course of these experiments the importance of incomplete spawning in females has become gradually recognised. A discussion on the fate of unspawned ova is given in 1, p. 974, and 6, where it is regarded as probable that in a few cases out of the large number of observations made a given female may as a result of incomplete spawning in the first instance have spawned successfully a second time in one season from one batch of ova matured for the first spawning.

Experiment 12 was designed to obtain information on this matter. It was found that among 98 surviving oysters examined in September 1926 (see Table XVII), 4 were carrying young, although all had been found previously in July with either embryos or larvæ. The condition of the young in two of these four cases indicated that spawning had occurred recently; it is possible, but not probable (owing to the small size of the larvæ), that in the two others the larvæ may have been retained in the mantle cavity from July. In Experiment 5, when 10 individuals were examined five weeks after detection with young, 1 had larvæ which had in all probability been retained during the five weeks. Thus retention of larvæ and incomplete spawning may give an appearance of the 
assumption of a second female phase in one and the same breeding season. Whether unspawned ova can be successfully spawned after remaining in the gonad during the winter is a moot point, though improbable. Eggs remaining in the gonad at the approach of winter are usually evacuated or begin to degenerate in situ in the gonad. Relict eggs may, however, contribute to hastening the next female phase by adding to the food reserves in the body by their absorption.

Apart from this, it may be considered that female spawning in the second summer due to incomplete egg-spawning in the previous summer is a rare event, if indeed it occurs at all. An individual which retains ova in the winter is usually of the type designated as "curdley" (see 1, Tables IV and IX).

In 1 , Table IV, p. 999, a record is made of the occurrence or absence of unspawned ova in about 700 recently spawning females. On analysis (see 6 ) it is found that about $54 \%$ retain few or more eggs after spawning ; $43 \%$ of these containing a few scattered eggs, while $11 \%$ may have many in scattered or large patches. Among this large sample as many as 22 individuals are recorded with the gonad from $\frac{1}{3}$ to $\frac{7}{8}$ spent. If it were possible for these individuals to spawn successfully again in the same season the percentage would attain the figure 3 , very nearly that found in Experiments 12, 7 and 5, namely 3.4. (See Tables XVII A and B.)

Thus the oysters bearing young again in September in Experiment 12 must be regarded as having almost certainly spawned a second time from eggs matured earlier in the season; it is also possible that others undergoing such a second spawning may have occurred undetected during the course of this experiment.

Among the experiments where the samples were opened in the second summer, the results obtained in Experiment 11A are especially interesting (see Table XVIII, sample 18). In this case there was little mortality during the winter, 41 surviving out of 48 . Correlated with these beneficent conditions is the occurrence of 3 oysters with young and 4 ripe female phases in the following July, a total of about $17 \%$ mature female-functioning reversions. In this set of experiments $11.7 \%$ of reversions occurred. Twenty per cent of reversion is also shown in Experiment 5, where the mortality in the preceding winter was low. Even if $5 \%$ of these be attributed to the influence of incomplete spawning in the preceding breeding season, there is still a significant margin left to prove reversion in the second summer, especially when it is remembered that the figure obtained is a minimum in comparison with that likely to occur in wholly natural animals.

In the small number of individuals surviving into the third summer, as in Experiment 4, one quarter of the sample were in mature female phases at the time of examination. 
Conclusions from Experiments on Oysters with Young.

The experiments therefore prove that oysters which have borne young in one summer do attain a new female phase and bear young again in significant (but small) numbers in the next summer; a rather larger proportion attained new female phases two years later. There is good reason to believe that the percentage of reversion to female phases will be very much higher in wholly natural than in the experimental oysters, and that more reversions occurred in the experimental oysters than were discovered.

\section{TABLE XVII A.}

Summary of Experiments on Isolating Oysters with Young. lst Summer.

2nd Summer.

$$
\text { No. of }
$$

O's

No. of No. of

\section{No: of} ㅇs No. of 3rd Summer.

\begin{tabular}{rccc} 
No. of & No. of & \multicolumn{2}{c}{ No.of with } \\
Expt. & oysters. & tests. young. \\
12 A & $82(56)^{*}$ & 1 & $2:$ \\
B & $3(2)$ & 1 & $0:$ \\
C & $28(25)$ & 1 & $2:$ \\
D & $15(15)$ & 1 & $0:$
\end{tabular}

13

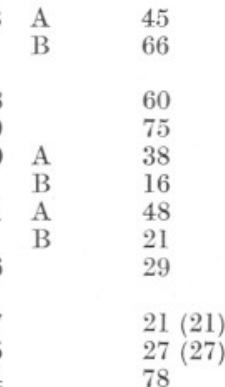

Totals

146

$\begin{array}{rrrr}38 & - & 8+2 & -: \\ 64 & - & 5+1 & -: \\ 38 & 2 & 1 & 4: \\ 48 & 2 & 0 & 2: \\ 28 & 1 & 2 & 0: \\ 7 & 1 & 1 & 0 \\ 41 & 1 & 4 & 3: \\ 6 & 1 & 1 & 0: \\ 20 & 2 & 1 & 2+1 ?\end{array}$
young. vivors. tests. and $\hat{\phi}$. you

2:

0 :

0 :

$19-3 \dagger$
$5-1 \dagger$
$32-4 \dagger$

4
4
3

\section{1 died \\ 02 died}

$1 \quad 19$ (3 died) $3 \quad 3+1$

$346 \quad 23+3 \ddagger \quad 16+1 ? \quad 19 \quad 3+1 \S$

sur- No. of ripe 's, wit

1st Summer

2nd do.

3rd do.

\section{TABLE XVII B.}

\begin{tabular}{|c|c|c|c|c|}
\hline $\begin{array}{l}\text { No. of } \\
\text { oysters } \\
\text { tested. }\end{array}$ & $\begin{array}{l}\text { No. of } \\
\text { functioning. } \\
\text { ripe } \text { 's's }\end{array}$ & $\begin{array}{l}\text { No. of } \\
\text { o's with } \\
\text { young. }\end{array}$ & $\begin{array}{c}\text { Total } \\
\text { functioning } \\
\text { ‥ }\end{array}$ & $\begin{array}{c}\text { Total \% } \\
\text { functioning } \\
\text { ㅇ. }\end{array}$ \\
\hline $146 \|$ & & & & \\
\hline $\begin{array}{c}346 \\
19\end{array}$ & $\begin{array}{c}23(+3)^{* *} \\
3(+1)\end{array}$ & $\begin{array}{l}16(+1 ?) \\
1\end{array}$ & $\begin{array}{r}39(+4) \\
4(+1)\end{array}$ & $\begin{array}{l}11 \cdot 3 \text { to } 12 \cdot 4 \\
21 \cdot 0 \text { to } 26 \cdot 3\end{array}$ \\
\hline $\begin{array}{l}511 \\
67 \|\end{array}$ & $26(+4)$ & $22(+1 ?)$ & $48(+5)$ & 10.8 to 11.9 \\
\hline
\end{tabular}

* The numbers in brackets in Table XVII A give those surviving to be tested in the first summer.

$\dagger$ Died during the second summer. $\quad \ddagger$ Intersexes with ova nearly ripe.

$\S$ With numerous doubtfully healthy ova.

i| Includes 48 from Experiments 7 and 5 carried forward or died at end of first summer.

- Includes 19 from Experiment 4 carried forward at end of second summer.

** The figures bracketed in Table XVII B are derived from the totals given in Table XVII A. 


\section{Sex-phases intervening Between Successive Female Phases.}

It has been shown (1, Table IV) that among 702 oysters carrying young $97 \%$ of such individuals immediately pass into an active male phase after the act of egg-spawning. Many hundreds of similar cases have since been recorded. Additional evidence is afforded by the sex-phases recorded in Table XVIII from the B series of experiments. Thus, there can remain no doubt that the translation from a female to an active male phase occurs normally in $O$. edulis after the egg-spawning act. The small percentage of abnormalities - which consisted mostly of no assumption of the male phase-occurred at the end of the breeding season, when the gonad is passing into a passive condition. This fact is quickly seen from a glance at Table XVIII, pp. 46-47. Among individuals examined in July (Sections 1, 4, and 6) the male-phases are predominant, and are mainly IV, V, and VI, indicating that the gonads are still producing spermmorulæ. On the other hand samples examined in September (Section 2) contain a high proportion of waning and neuter phases (e.g. VI, VII, and VIII). At the beginning of the second summer male phases still occur in high proportion, but are predominantly active, and it is interesting to note contain some quite young phases, namely I to III. It is thus shown that at the end of the breeding season sperm-production wanes or ceases but becomes active again in a high proportion of comparable individuals $(80 \%)$ in the following early summer. During the early summer a proportion of individuals varying in the experimental material from $10 \%$ to $15 \%$ pass over into a functional female phase. A comparison of the totals in Sections 2 and 3 in the Table gives the suggestion that a proportion of the neuter individuals in September become female in the following spring. Further evidence is required, however, before this sequence can be acclaimed as a fact. No data are available from these experiments for discovering what proportion of individuals would pass from 2nd summer male phases into a 2 nd summer female phase, but it is hoped to obtain the required information from an intensive study of seasonal changes in sex-phases in an oyster population. Such a study was made in 1926-27, and the results are being worked out.

In the 3rd summer the female phase was assumed in a larger proportion of the experimental oysters; $50 \%$ in Series A (see Table IV, p. 27) and $21 \%$ to $26 \%$ in Series B (see Table XVII B, p. 44), excluding the individuals showing signs of having recently passed through the female phase by the presence of recently relict ova in the gonad. Under wholly natural conditions there can be little doubt that the percentage of these transitions to the female phase would be much higher than in the experimental. The experiments nevertheless afford a valuable basis for more enlightening field studies. For example, it is relevant to record that in 
SEX-PHASES of 0. EDULIS, occurring in samples examined at

(Data derived from material

No. of

Sec-Sam. tion. ple.

1.

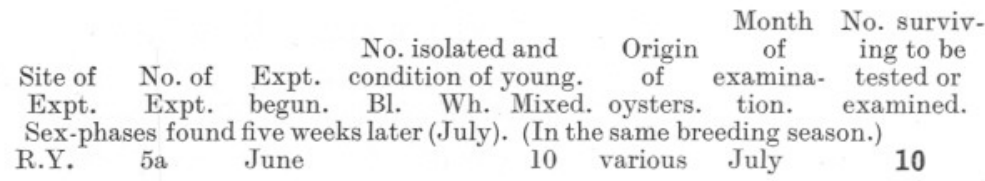

2. Sex-phases found two to three months later in the 1st summer (Sept.-Oct.), (within

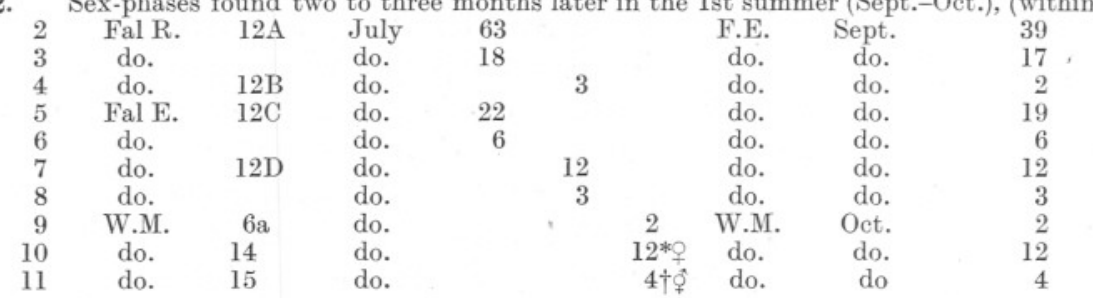

Totals of Section 2

3. Sex-phases found at the approach of the next breeding season (2nd summer; May).

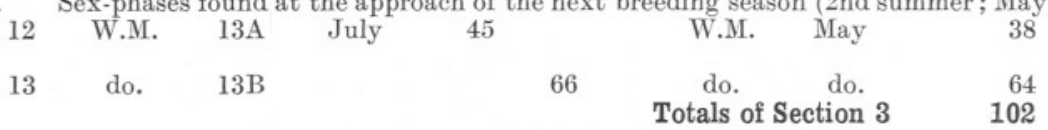

4. Sex-phases found during the next breeding season (2nd summer; July).

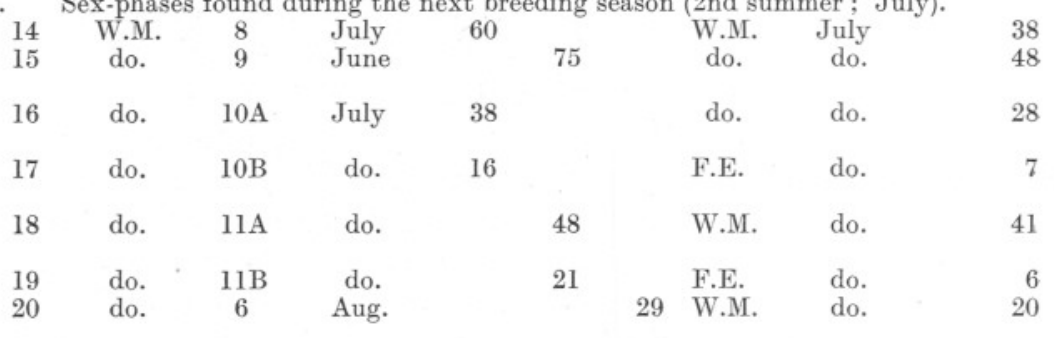

Totals of Section 4

188

5. Tested only for young-bearing in the next breeding season (2nd summer; ca. July).
$\begin{array}{llll}21 & \text { W.M. } & 4 & \text { July } \\ 22 & \text { R.Y. } & 5 & \text { June } \\ 23 & \text { R.Y. } & 7 & \text { June- }\end{array}$
78 W.M. July $32-4$
Aug.
27 various do.
$5-1$
21 do. June-Aug. 19-3
Totals of Section 5
56

6. Sex-phases found two years later (3rd summer; July). 24 W.M.
(78) W.M.
June-July

16

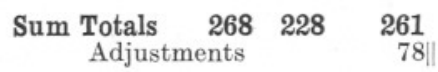

488

\section{Adjusted Totals $\quad 6 \% 9$}

* 12 found as ripe female by boring the shell.

$\dagger 4$ found as ripe $\oint_{\uparrow}^{*}$ by boring the shell.

* Comprises some samples not shown in Table XVII (i.e.

1. 2. 3. The small figures give the number of individuals in the $\phi$ The numbers in brackets are included in one or other of the औ 78 individuals used for Sample 21, Experiment 4, are recorded 


\section{XVIII.}

various intervals of time after being detected with young.

isolated in cages in the sea).

Female phases.

Male phases.

\section{Ripe phases.}

No. of

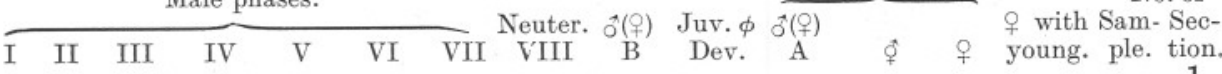

$\begin{array}{lll}3 & 3 & 3\end{array}$

11

but at the end of one and the same breeding season).

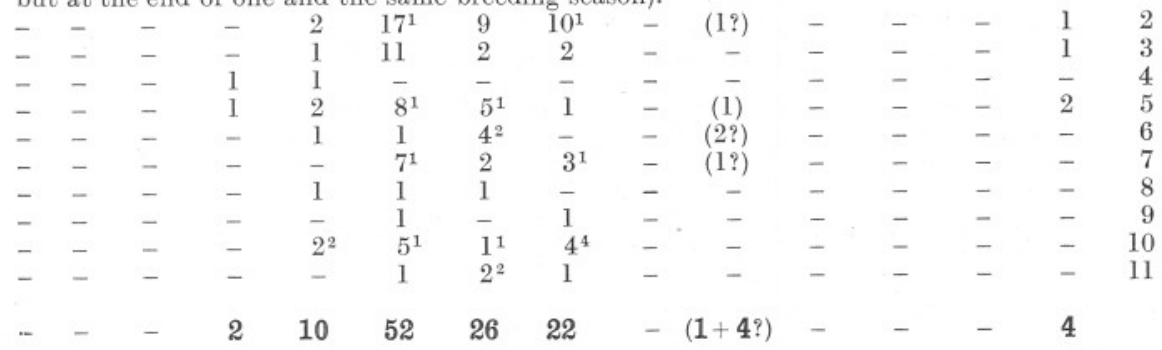

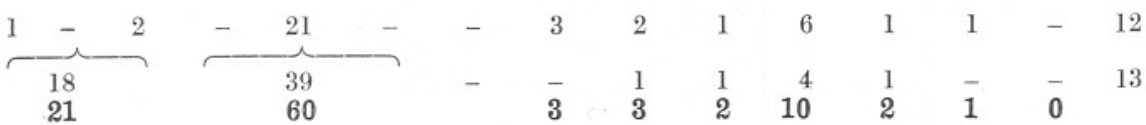

3.

2.

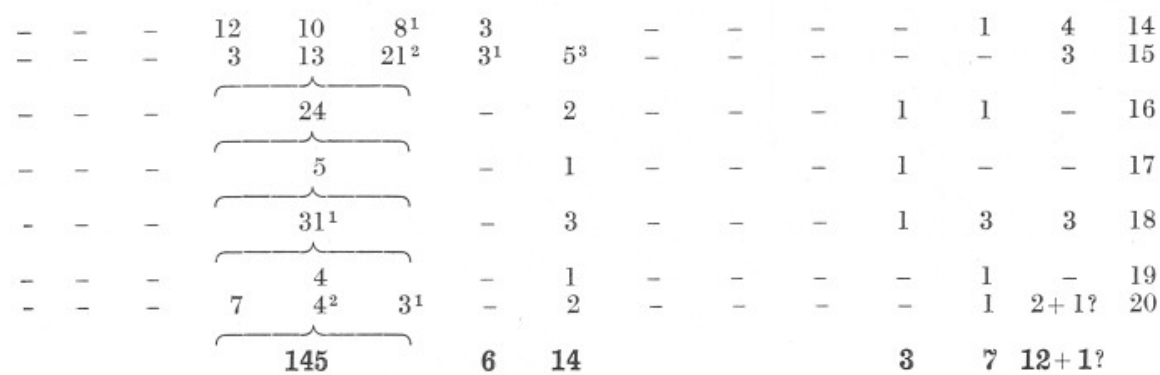

4.

samples 1, 9, 10, 11) and sample 24 counted twice.

respective phases with either small patches of unspent or-rarely-developing ova in the gonad.. male phases and are not to be counted in the sample total.

again in Sample 24, Experiment $4 \mathrm{c}$. 
three successive seasons on the Fal Estuary beds (Truro Rights) about $50 \%$ of the oyster population have been found to be ripe as functional females at about the beginning of each breeding season (see also \%, p. 27). These facts alone show that on these beds there is on the average a reversion to the female phase at least every other summer.

A comparison of the male phases of the oysters in the experiments of Series A (see Table IV A, p. 27) with the male phases of individuals which were females in the preceding summer (see Table XVIII, Section 4, pp. 46-47) brings out a close similarity. Hence the males used in the Series A may have been mostly female in the summer before that in which they were identified. Some of these might very well have been female two summers ago, and therefore the rapid change to female observed in one instance (see p. 24) is - in the light of the results of these experiments and if the individual were normal - not outside expectation.

The young female stage was observed in two individuals in Experiment 13 when the whole sample was opened at the approach of the breeding season in May.* Seasonal studies have proved that the bulk of the females in an oyster population develop rapidly in the spring and early summer, hence examinations made about April-July would be the most favourable for discovering young females on most English beds. The relatively small proportion of all the different types of female phases found in the experiments is important in indicating :-

(1) that there is no automatic return to the female phase in the 2nd or the 3rd summer after that (counted as the 1st summer) in which young are borne.

(2) A return to the female phase may occur in the following breeding season (2nd summer) in a small but significant proportion of individuals.

(3) A higher proportion may revert to the female phase in the 3rd than in the 2 nd summer.

(4) The male phase following egg-spawning may persist throughout the 2 nd summer and possibly in the $3 \mathrm{rd}$ summer.

It is emphasized that these are experimental results, and that there is virtual certainty that the sexual processes follow each other more rapidly and more regularly on the oyster grounds than is apparent from these experiments.

Intersexes, or various hermaphrodite conditions, occur in most of the experimental samples which were examined after the 1st summer, and are especially abundant in Experiments 12 and 13 (see Section 3, Table XVIII). This result in a sample examined in May is in accordance with

* Great caution is required in assessing young ova in recently-spawned individuals; in these cases young ova are not infrequently retained in the gonad (see Section 2, Table XVIII). 
the findings from seasonal studies, in which it has been proved (unpublished) that the female phase may be assumed very rapidly and superimposed upon a variety of the male phases.

Thus the experiments show that after an oyster has spawned as a female a sperm-producing phase is assumed automatically (with rare exceptions at the end of the breeding season). Sperm-production is active for about one month and then wanes. At the approach of autumn when foodreserves are usually being accumulated, the gonad assumes a quiescent condition in a large proportion of individuals, but in some remains still active. In the first winter the gonad remains apparently in either a neuter condition or in arrested and mostly late male phases. In the following spring a new phase of male activity may begin, or the arrested male phase be continued. In some cases an active female phase is superimposed upon neuter individuals to give pure females, or upon a variety of male phases to give various types of hermaphrodites. These intersexes with ripe newly formed ova are with little doubt mostly, if not all, femalefunctioning, but are not all definitely proved to be of this nature by the experiments herein described (see p. 19 (c), and Experiment 15, p. 38); the rarity of purity found (unpublished researches) amongst apparently pure ripe females enhances the probability that these types of intersex produce larvæ.

\section{DISCUSSION AND CONCLUSIONS.}

The experiments herein described prove definitely for the first time that male individuals of $O$. edulis pass into the female condition in significant proportion within twelve months and that greater proportions attain the female condition in two years. The experimental conditions render it probable :-

(1) that only a proportion of the actual change over to the eggproducing stage in the experimental material has been observed, and

(2) that the actual changes in the experiments into female phases are less than would occur naturally when the molluses lie free on the grounds.

For these reasons it is considered advisable to obtain further information on the rate and proportion of the change from the male to the female phase from studies in seasonal changes in sex-condition throughout an oyster population. Data for such a study have already been obtained, and will be discussed in the near future.

It would appear to emerge from the experiments-in accordance with expectation - that the change from male to female is not automatic as is the change from female to male. The age of the experimental oysters 
was not known definitely, although it could be stated with certainty that the bulk of the individuals ranged between 4 and 6 years. It is conceivable that the period elapsing between successive female phases may vary with age, but the fact that $O$. edulis may under optimum conditions become female at an age of one year (8) on English oyster beds indicates that age is not an all-important factor. The predominant factor in the change from the male to the female phase would seem to be the experience of a period of anabolic metabolism ; for this, abundant food and healthy conditions in general are required. In some of the experiments these conditions were certainly not fulfilled during the whole period of the experiments.

The small proportion of reversions to the female phase in about twelve months and the larger proportion after two years indicates that the normal period intervening between successive female phases may be two years on English beds. Many of the experiments were not, however, designed to run for two years, and in those maintained for that period the conditions (e.g. continual testing) were admittedly bad. In new experiments in the future it would be advisable to leave some of the experimental oysters in the sea undisturbed, except for cleaning, for two years, in order to maintain the best possible conditions for determining the percentage of reversion to the female phase for this period of time.

\section{SUMMARY,}

Under such environmental conditions as occur on English oyster grounds, it has been found by the use of experimental cages that oysters proved to be male in a given breeding season change to functional females in significant numbers (a minimum of $10 \%$ to $16 \%$ ) in the next breeding season: among a small number of survivors $50 \%$ became functional females within about two years.

Experiments on isolating in the sea oysters which have been found with young prove also that a significant number of individuals (ca. 11\%) revert to mature female phases within about twelve months; in experiments extending over two years a higher proportion (a minimum of $21 \%$ ) among a small number of survivors reverted to mature female phases under conditions which are known to have been and were necessarily unfavourable.

Owing to experimental difficulties, which are discussed, it is considered highly probable that the proportion of changes or reversions to the female phase detected is smaller than that actually occurring in the experiments and evidence is advanced that it is much smaller than occurs when the oysters are lying free and undisturbed on the oyster-bed.

On the other hand it is also shown that a small proportion of individuals 
(about 3\%) may spawn twice in one breeding season from one batch of eggs if a high degree of incomplete spawning occurs at the first attempt. The bearing of this phenomenon on the experimental results is discussed.

The experiments indicate that two years may be the more usual period intervening between successive normal female phases on English oyster beds, but new experiments conducted on different lines are required to obtain further direct information on this problem. This result is in harmony with statistical investigations, which show that females revert to the female phase at least every other breeding season.

The sex-phases found by experiment to intervene between successive female phases are recorded and discussed.

While providing important facts it is regarded that the experiments are inadequate to give a representation of the natural phenomena, and that a clearer picture of the natural changes is more likely to be obtained from a comprehensive population study, for which the experimental results herein described will provide a solid basis.

\section{On Experiments with Oysters in Cages.}

It is an interesting and somewhat surprising fact that the isolation of oysters in a cage on the natural oyster bed introduces in itself an important modification of the natural habitat. In the cages utilised in the later experiments herein described a large mesh ( $1 \frac{1}{2}$ inches in diameter) was utilised, as it was soon realised that the $\frac{3}{8}$-inch mesh of the cage used at West Mersea too readily permitted an accumulation of mud. There are, however, limits to the size of mesh which can be used with safety, for any of the bivalves may slip or project partially through a mesh and in that way be prevented from opening or growing shell-shoots properly. The mesh prevents so free a flow of water over the isolated oysters as occurs on the neighbouring ground. As a consequence an accumulation of silt occurs in the cage, especially if large numbers of the larger simple Ascidians, e.g. Ciona, Ascidiella aspersa and Ascidia conchilega settle on the oysters or cage and grow; their excreta add to the accumulation of silt in the cage. Silt settling in this way may either choke the oysters or interfere very seriously with normal nutrition by necessitating a large intake of silt in feeding with the consequent loss of energy in voiding it. To obviate some of these disadvantages the cage was raised off the bottom on a table structure; this arrangement gave better results than a cage lying directly on the bed. The disadvantages of a table-cage are that it is more difficult to put out and is more easily upset while lying at the bottom. On a commercial bed it is inadvisable to buoy a cage since the buoy-ropes may inadvertently be fouled by ships passing in the dark. 
To prevent the accumulations of growth and silt in the cage it is advisable to raise it as frequently as possible. With a table-cage moored on the bottom frequent cleansing in this way is a laborious and expensive process, unless the experimenter be working continuously near the site of the experiment. A cage lying directly on the bottom can be relatively easily raised and cleaned on frequent occasions. Attachment of the anchors to the legless cage can be made upon the strong iron framework around which the iron mesh-work is secured. Pairs of handles along each edge of the cage at the top as well as the bottom were found extremely useful for one or other of the operations.

It is important to have the cage constructed so that every compartment can be recognised without a label, and the provision of iron-wire mesh shelves in each compartment is an additional advantage for isolating special oysters of different classes easily and quickly. If a permanent shelf be provided it is easy to construct a cover to make a new cagelet within any compartment. In a later design permanent but short legs were obtained by simply allowing the strong vertical corner rods of the framework to project beyond the bottom of the cage. A design of this kind is useful in certain kinds of experiments, though the legs may require strengthening in other ways if much weight is carried. In making the centrally placed lid regard must be paid to the accessibility of the recesses of the different compartments, but the safety accruing from the central lid is a compensation for a little trouble in handling the experimental material.

\section{Acknowledgments.}

All the experiments herein described were carried out as a part of the programme of research work of the Marine Biological Association, Plymouth, with the approval of the Council and the unfailing help of the Director, Dr. E. J. Allen.

Reference has been made to the valuable help in this work given especially by the Tollesbury and Mersea Native Oyster Company, without whose co-operation and good-will most of the experiments could not have been done. Similar valuable assistance was given also by the Yealm Oyster Fisheries and the Oyster Committee of the Truro Corporation. All these bodies, as well as the Seasalter and Ham Oyster Co., and the Duchy Native Oyster Co., helped to provide the experimental oysters by -in some cases unusual-dredging in the breeding season.

In the operations in the field I am especially indebted to Mr. Louis French, Mr. Bert French, Mr. W. M. Mole, Mr. J. Kingcome, Mr. E. Searle, and Mr. W. Searle for suggestions and assistance in handling the experimental apparatus. 
Mr. J. Metherell, of Plymouth, had no difficulty in making the experimental cages; the late Mr. O. Anstey constructed the table apparatus.

I am indebted to Misses D. E. Coleman and H. M. Lewis for assistance with the manuscript and proofs, to Mr. P. Bond for the photos for Fig. 3, and enlargements of field photos, and to Mr. A. J. Smith for the photo for Fig. 1, Part III.

For a number of years small grants in aid of the expenses were received from the Royal Society and were utilised on some occasions for making highly desirable additional visits to West Mersea from Plymouth. It is a pleasure to acknowledge the usefulness of these grants.

\section{REFERENCES.}

1. Orton, J. H. Observations and experiments on sex-change in the European oyster $(O$. edulis). Part I. The change from female to male. Journ. Mar. Biol. Assoc., N.S., Vol. XIV, No. 4, 1927.

2. - Do. Part II. On the gonad of egg-spawning individuals. Journ. Mar. Biol. Assoc., N.S., Vol. XVII, 1931.

3. - On rhythmic periods of shell-growth in $O$. edulis with a note on fattening. Journ. Mar. Biol. Assoc., N.S., Vol. XV, No. 2, 1928.

4. — British Oyster Fisheries. Nature, Vol. CXXIII, 1929.

5. — (assisted by E. Worsnop). An account of investigations into the cause or causes of the unusual mortality among oysters in English oyster beds during 1920 and 1921. Part I. Report, Fisheries Investigations. England and Wales. Series II, Vol. VI, No. 3, 1923 (1924).

6. - Observations and experiments on sex-change in the European oyster (O. edulis). Part III. On the fate of unspawned ova. Journ. Mar. Biol. Assoc., N.S., Vol. XIX, 1933.

7. _ - On lunar periodicity in spawning of normally grown Falmouth oysters (O. edutis) in 1925. Journ. Mar. Biol. Assoc., N.S.,Vol. XIV, No. 1, 1926.

8. - - Phenomena and conditions of sex-change in the oyster (O. edulis) and Crepidula. Nature, Vol. CX, 1922, p. 212.

9. ORton, J. H., and Lewis, H. M. On the effect of the severe winter of 1928-1929 on the Oyster Drills . . . of the Blackwater Estuary. Journ. Mar. Biol. Assoc., N.S., Vol. XVII, 1931. 
